\title{
Investigation of Yarn Quality in Ring Yarn by Modifying Bottom Apron/Nose Bar with Perforations and Air-Suction
}

\author{
Bantamlak Birlie ${ }^{1, *}$, Sampath Rangaraj ${ }^{2}$ \\ ${ }^{1}$ Department of Textile Engineering, College of Engineering and Technology, Wolkite University, Wolkite, Ethiopia \\ ${ }^{2}$ Department of Textile Engineering, Bahir Dar University, Bahir Dar, Ethiopia
}

Email address:

bantamlak.birlie@wku.edu.et(B. Birlie),samsid3@rediffmail.com (S. Rangaraj),samsiddd3@gmail.com (S. Rangaraj)

${ }^{*}$ Corresponding author

\section{To cite this article:}

Bantamlak Birlie, Sampath Rangaraj. Investigation of Yarn Quality in Ring Yarn by Modifying Bottom Apron/Nose Bar with Perforations and Air-Suction. American Journal of Applied Scientific Research. Vol. 7, No. 3, 2021, pp. 56-76. doi: 10.11648/j.ajasr.20210703.14

Received: August 30, 2021; Accepted: September 14, 2021; Published: September 26, 2021

\begin{abstract}
Currently, ring spinning has limitations of poor integration of fibers that protrude from yarn surface, which causes hairiness and irregularity. The aim of this research is to improve yarn quality by modification of bottom apron/nose bar with perforation and applying air-suction in a conventional Reiter G35 ring frame and spinning 29.52 Tex (20 Ne) and 14.76 Tex $(40 \mathrm{Ne})$. To produce modified yarn 17 combinations of apron hole diameter, suction pressure, and widthwise hole distance was used. The ANOVA result shows that as suction pressure increases hairiness, tenacity, and thick place $(+50 \% / \mathrm{km})$ were improved significantly for both counts. Based on the result suction pressure, apron hole diameter, and hole distance were optimized to 23.9 mbar, $1.58 \mathrm{~mm}$ and $10 \mathrm{~mm}$ respectively for $40 \mathrm{Ne}$ and $25 \mathrm{mbar}, 1.75 \mathrm{~mm}$, and $11.6 \mathrm{~mm}$ respectively for 20 Ne. As compared with conventional hairiness, tenacity, thin place, and thick place of $40 \mathrm{Ne}$ modified yarn were improved by $16.25 \%, 12.7 \%, 17.42 \%$, and $14.62 \%$ respectively. Whereas hairiness, tenacity, and thick place of 20 Ne modified yarn were improved by $8.87 \%, 7.42 \%$, and $18.2 \%$ respectively. Thus, the modified G35 method of yarn condensing has capability to be used as an alternative method of conventional spinning as it is capable of producing better quality yarn.
\end{abstract}

Keywords: Apron Hole Diameter, Condensed Yarn, Suction Air Pressure, Hole Distance, Yarn Quality

\section{Introduction}

The textile industry is more competitive today than ever in an attempt to produce high-quality clothes at minimal production costs that meet both the aesthetic and technical needs of todays' generation [1]. The current competitive market requires designers of the fabric to consider moisture absorption and wick ability properties depending on weather conditions and end-use applications [2].

The quality of the spun yarn is significantly improved by using quality raw material, suitable selection of spinning system, and type of spinning machine [3, 4]. The main objective of yarn spinning is to achieve the highest predictable yarn evenness with minimum imperfections, which imparts uniformity in yarn strength. Therefore, these improvements positively influence the quality of subsequent processes, like weaving and knitting $[5,6]$.

Different spinning is anticipated to take into consideration the characteristics of fiber machine intelligence, which assists to modify ideal combinations of fiber properties $[7,8]$. The attempts to produce high-quality yarns have been concerned with great developments in the area of spinning [9]. These developments consist of examining, manufacturing, and optimizing various mechanisms and settings in spinning to modify conventional rings by introducing new elements or developing entirely new yarn production systems. Therefore, yarn quality refers to the physical characteristics of a yarn that influence fabric production, performance, and serviceability. These parameters include yarn hairiness, yarn strength, imperfection, and yarn evenness $[10,11]$.

The measures to produce better quality yarns are detection and reduction of raw material variation, reduction in coefficient of variation, and elimination of faults, which is a significant increase in yarn breaking force and elongations. 
In addition, supervision, and control of all processes, finding optimum settings over all technologies, and use of automation according to existing mill settings are required $[10,11]$. The further developments in ring spinning were leading to a modification of ring-spinning such as compact, double-rove, solo, nozzle-ring, and core-sheath, etc., have improved the versatility of ring spinning [8, 12]. The significant limitation of ring spinning is its low productivity, the yarn quality it produces, namely high yarn hairiness especially hairs longer than $3 \mathrm{~mm}$, and irregularity. The latter is characteristic of roller drafting, which is unable to perfectly regulate the movement of short fibers and spinning geometry [13]. The introduction of compaction of fiber strand in the ring by various compact spinning reduces the problem of excessive hairiness in-ring yarns. But, the problem of hairiness variation along the length of yarn remains unsolved and will remain due to no individual control of fibers in drafting [8].

The basic modification takes place in the region of the spinning triangle. The arrangement of fiber in yarn structure is not similar to one another but all yarn is twisted by the same principle as the conventional ring. Using an air-suction device and a perforated surface mounted on the fiber flow line, fiber at the selvage of the fiber strand is completely integrated into the yarn body, thus increases yarn strength with a decrease in hairiness [14]. The drafted fiber strand in compact spinning is condensed before the twist is imparted; the fibers are arranged in a close and parallel position to one another. Improved characteristics of yarn after compacting the yarn are perfect structure thus increases yarn strength, reduces hairiness, and improved abrasion resistance [15].

The physical properties of the yarn like the tenacity and evenness of the yarn spun with the compact spinning system was higher as compared with ring yarn [16]. Generally, the ring-spun yarn has a higher imperfection index compared to compact-spun yarns $[15,17]$. Fabrics woven with compact yarns have more tensile strength, and extension than fabrics woven with ring yarns [17]. There is a significant change in the physical properties of fabrics produced by compact and ring yarn concerning abrasion resistance, breaking, and tearing strength [18].

The conventional ring has been modified to produce condensed yarn with air suction pressure fitted in the front drafting zone. The reduction in yarn hairiness can be attributed to better binding of the edge fibers in the drafted ribbon due to the mingling action of air at the front drafting zone [19]. The improvements in yarn imperfection are due to the compaction of the drafted ribbon at the front drafting zone causes a higher fiber-to-fiber cohesion, which leads to better control on short fiber motion while drafting. The condensed yarns are found to be stronger and more extensive than existing ring yarns [19]. Compressed air is applied to yarn, the swirling airflow tucks ring yarn surface fibers into its body, thereby improves the consistency of yarn and reduces hairiness. Thus, applying an air nozzle significantly lowers the degree of hairiness of spun yarn [20]. Therefore, the existing literature supports the idea that yarn quality can be improved to a large extent by modifying the conventional ring spinning system. These reasons initiate the interest to further study, investigate, and manipulate the conventional ring spinning process to produce better quality yarns.

\section{Materials and Method}

\subsection{Modifications of Conventional Ring Spinning}

The bottom apron YAMADICHI 16.04 model with dimensions of $228 \mathrm{~mm} * 30 \mathrm{~mm} * 0.9 \mathrm{~mm}$ bottom aprons were perforated as shown in Figure 1. The bottom aprons were perforated with $1 \mathrm{~mm}, 1.5 \mathrm{~mm}$, and 2 mmholediameter with widthwise hole distance $10 \mathrm{~mm}, 12 \mathrm{~mm}$, and $14 \mathrm{~mm}$ separately for each hole diameter [21]. Perforation has been done in two rows on the bottom apron; thus 23 pairs of holes were perforated in each apron. The perforation distance in case of perforating the next zigzag hole was $2 \mathrm{~mm}$. Finally, the distance of the hole for each row on the same axis of the apron was $4 \mathrm{~mm}$ because the fiber length under $4-5 \mathrm{~mm}$ is lost in processing as waste and fly [22]. The nose bar was fabricated as shown in Figure 1 with dimensions $53 \mathrm{~cm} \times 2.5$ $\mathrm{cm} \times 0.4 \mathrm{~cm}$ and perforated for extending and tensioning the bottom apron to the nip line of the front roller.

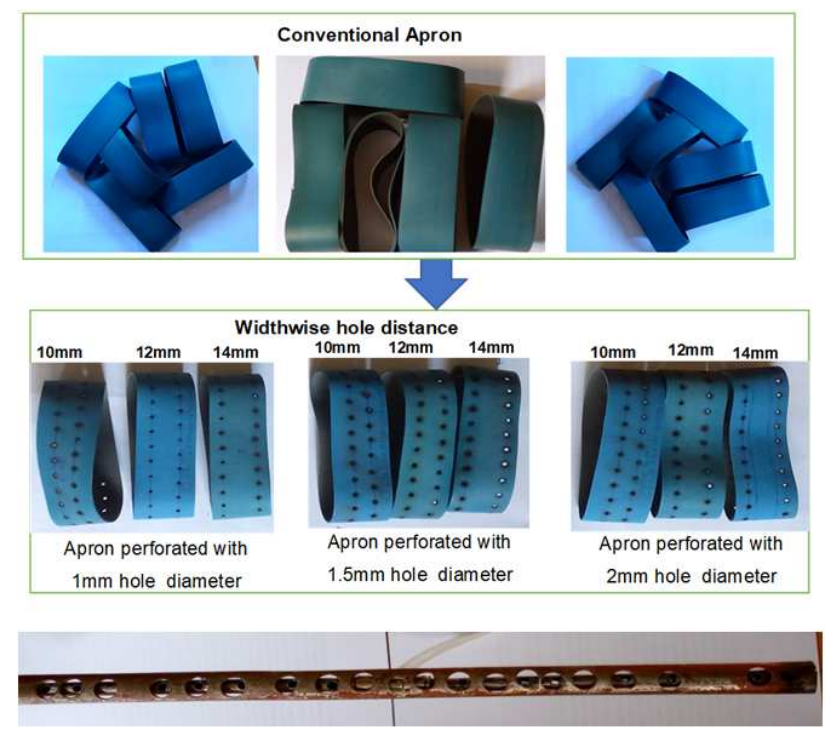

Figure 1. Modified or perforated bottom apron and nose bar.

The conventional G 35 ring frame the drafting arrangement was modified by perforating the bottom apron. The diameter of the needle was $1 \mathrm{~mm}, 1.5 \mathrm{~mm}$, and $2 \mathrm{~mm}$ for perforating the aprons [6, 23-32]. Pneumatic suction pipelines for each spindle was installed under the perforated bottom apron for sucking protrude fibers by measuring with a pressure gauge.

\subsection{Methods}

Figure 2 described the overall method of the study in the flow diagram starting from the initial machine modification to yarn production. After the preparation of the test specimen, all the yarn is tested in the standard testing condition $65 \pm 2 \%$ relative humidity and temperature $20 \pm 2^{\circ} \mathrm{C}$. 


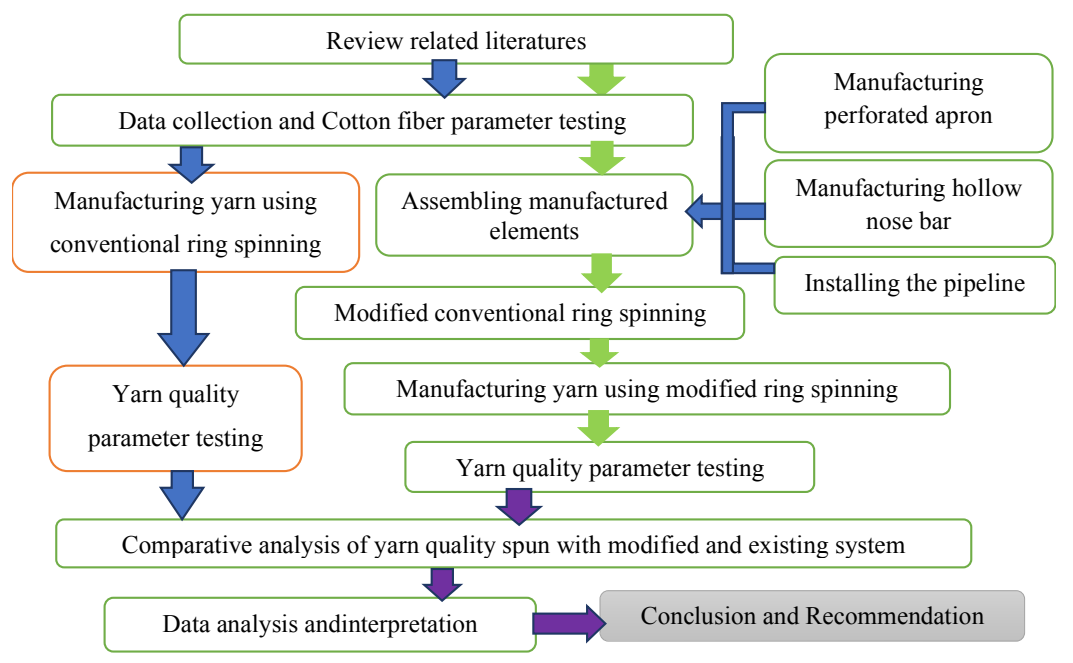

Figure 2. Methodology.

\subsubsection{Fiber Parameters Test by HVI/1000}

The $100 \%$ cotton fiber quality parameters were tested with Uster HVI 1000 as shown in Table 1 such as tenacity, UHML, short fiber content, maturity, elongation, and micronaire were tested.

Table 1. Fiber quality parameters.

\begin{tabular}{|c|c|c|c|c|c|c|c|c|c|c|c|}
\hline Fiber parameter & SCI & Mst (\%) & Mic & Mat & UHML (mm) & UI (\%) & SF (\%) & Tenacity (g/tex) & Elon (\%) & Rd & $+\mathbf{b}$ \\
\hline Average & 82 & 4.9 & 3.56 & 0.83 & 24.99 & 79.2 & 11.7 & 17.7 & 7.1 & 78.9 & 9.3 \\
\hline
\end{tabular}

\subsubsection{Yarn Spinning}

For manufacturing the yarn using modified and conventional rings all machine settings and process parameters were the same as shown in Table 2.

Table 2. Ring frame machine settings for the modified and conventional yarn.

\begin{tabular}{lllll}
\hline \multirow{2}{*}{ Parameters } & \multicolumn{2}{l}{ Conventional G 35 ring } & Modified G 35 ring & $\mathbf{4 0 ~ N e}$ \\
\cline { 2 - 5 } & $\mathbf{2 0 ~ N e}$ & $\mathbf{4 0 ~ N e}$ & $\mathbf{2 0} \mathbf{~ N e}$ & 1.1 \\
\hline Roving count (Ne) & 0.8 & 1.1 & 0.8 & 1080 \\
Twist (Tpm) & 820 & 1080 & 820 & 16500 \\
Spindle speed (rpm) & 10000 & 16500 & 3.75 & 3.5 \\
Spacer & 3.75 & 3.5 & 2 & $4 / 0$ \\
Traveller number & 2 & $4 / 0$ & 12.2 & 15.3 \\
Delivery speed (m/min) & 12.2 & 15.3 & 25 & 39 \\
Total draft & 25 & 39 & & \\
\hline
\end{tabular}

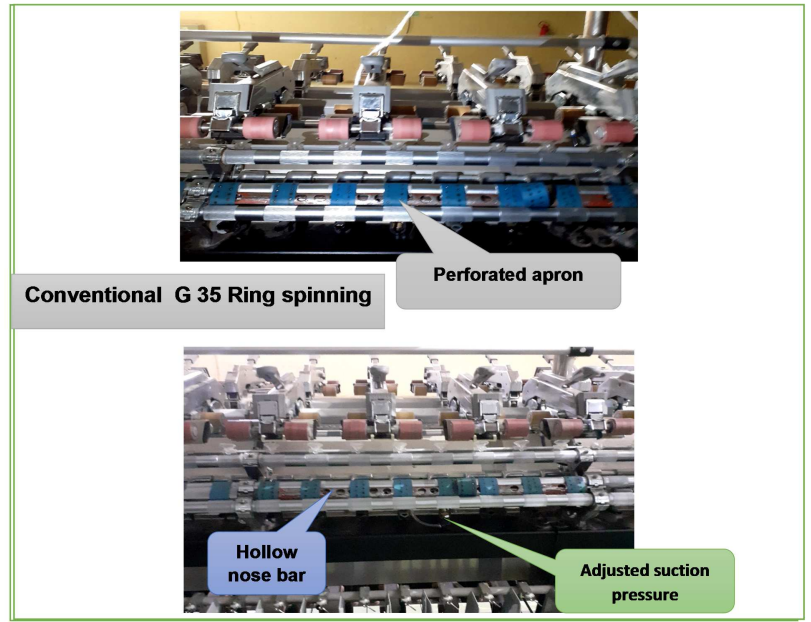

Figure 3. Modified G 35 ring spinning.
Figure 3 shows existing and modified yarns spun in Reiter G35 with 17 combinations of apron hole diameter, suction pressure, and widthwise hole distance on a modified G 35 ring.

Yarn property parameters spun with existing and modified $\mathrm{G} 35$ ring were tested. The analysis was done by design expert with Box-Behnken design and comparison was done by independent samples t- test using Analysis of Variance (ANOVA) statistical software were used.

\section{Results and Discussion}

The yarn property test investigation was analyzed based on a 95\% confidence interval. The degree of significance (p), which has been obtained from ANOVA, has been compared with the significance level $(\alpha)$ of 0.05 . The effects, whose degree of significance has been lower than 0.05 , have been interpreted as statistically important. 


\subsection{Effect of Apron Hole Diameter, Suction Air Pressure, and Width-wise Hole Distance on Properties 40 Ne Ring Yarn}

Table 3 shows the average yarn test result for 40 Ne yarn spun on the modified G 35 ring.

Table 3. Average test results for 40 Ne yarn spun with modified $G 35$ ring with different combinations.

\begin{tabular}{|c|c|c|c|c|c|c|c|c|}
\hline & Factor 1 & Factor 2 & Factor 3 & Response 1 & Response 2 & Response 3 & Response 4 & Response 5 \\
\hline Run & $\begin{array}{l}\text { A: Apron hole } \\
\text { diameter }(\mathrm{mm})\end{array}$ & $\begin{array}{l}\text { B: Suction pressure } \\
\text { (mbar) }\end{array}$ & $\begin{array}{l}\text { C: Widthwise hole } \\
\text { distance }(\mathrm{mm})\end{array}$ & $\begin{array}{l}\text { Tenacity } \\
\text { cN/tex }\end{array}$ & $\begin{array}{l}\text { Hairiness } \\
\text { Index }(\mathrm{H})\end{array}$ & $\begin{array}{l}\text { Nep } \\
(+200 \% / \mathbf{k m})\end{array}$ & $\begin{array}{l}\text { Thin place } \\
(-50 \% / \mathrm{km})\end{array}$ & $\begin{array}{l}\text { Thick place } \\
(+50 \% / \mathbf{k m})\end{array}$ \\
\hline 1 & 2 & 15 & 12 & 9.094 & 6.19 & 3287 & 337 & 1892 \\
\hline 2 & 1.5 & 20 & 12 & 13.483 & 5.58 & 3472 & 335 & 1547 \\
\hline 3 & 1.5 & 20 & 12 & 13.927 & 5.53 & 2395 & 285 & 1494 \\
\hline 4 & 1.5 & 20 & 12 & 12.423 & 5.56 & 2515 & 305 & 1556 \\
\hline 5 & 1 & 15 & 12 & 8.789 & 6.28 & 4252 & 347 & 2036 \\
\hline 7 & 1.5 & 25 & 10 & 16.595 & 5.37 & 1896 & 165 & 1384 \\
\hline 8 & 1.5 & 15 & 10 & 12.969 & 5.77 & 2683 & 236 & 1521 \\
\hline 9 & 2 & 25 & 12 & 10.961 & 6.03 & 3561 & 314 & 1785 \\
\hline 10 & 1 & 20 & 14 & 8.985 & 6.32 & 3613 & 370 & 2040 \\
\hline 11 & 1.5 & 20 & 12 & 14.069 & 5.64 & 2281 & 300 & 1481 \\
\hline 12 & 2 & 20 & 14 & 7.892 & 6.37 & 3357 & 357 & 2010 \\
\hline 13 & 2 & 20 & 10 & 14.107 & 5.41 & 3146 & 169 & 1342 \\
\hline 15 & 1.5 & 25 & 14 & 8.341 & 6.24 & 4227 & 345 & 1838 \\
\hline 16 & 1 & 20 & 10 & 13.718 & 5.79 & 3863 & 234 & 1482 \\
\hline 17 & 1.5 & 15 & 14 & 8.362 & 6.39 & 4265 & 356 & 1963 \\
\hline
\end{tabular}

\subsubsection{Hairiness Index $(\mathrm{H})$}

The ANOVA in Table 4 shows that the model F-value obtained in the present study was 80.79 implies the model is significant. In this study, apron hole diameter (A), suction pressure $(\mathrm{B})$, and widthwise hole distance $(\mathrm{C})$, interaction effect $(\mathrm{AC})$, besides quadratic terms $\left(\mathrm{A}^{2}, \mathrm{~B}^{2}\right.$, and $\left.\mathrm{C}^{2}\right)$ have a significant effect on the hairiness of $40 \mathrm{Ne}$ yarn. The hole distance had the highest F-value of 393.83 implies that it has the most significant influence on the hairiness of $40 \mathrm{Ne}$ yarn. However, the interaction effect (AB), and (BC) has no significant effect on the hairiness.

A quadratic model for hairiness of $40 \mathrm{Ne}$ yarn from
ANOVA, in terms of coded parameters after removing nonsignificant model is given in Equation (1). The regression model shows that the hole diameter (A) and suction pressure (B) have a negative correlation with hairiness of $40 \mathrm{Ne}$. The holes distance $(\mathrm{C})$, interaction effect $(\mathrm{AC})$, and quadratic term $\left(\mathrm{A}^{2}, \mathrm{~B}^{2}\right.$, and $\left.\mathrm{C}^{2}\right)$ have a positive correlation with hairiness of $40 \mathrm{Ne}$ yarn. Thus, the model as shown in Equation (1) predicts that the linear effects of hole distance (C), interaction effect $(\mathrm{AC})$, and quadratic term $\left(\mathrm{A}^{2}, \mathrm{~B}^{2}\right.$, and $\mathrm{C}^{2}$ ) decreases the yarn hairiness for $40 \mathrm{Ne}$ decreases. However, as apron hole diameter (A) and suction pressure (B) increases the hairiness index decreases.

$$
\text { Hairiness index }(H)=+5.59-0.06 \mathrm{~A}-0.1125 \mathrm{~B}+0.3725 \mathrm{C}+0.1075 \mathrm{AC}+0.2928 \mathrm{~A}^{2}+0.2627 \mathrm{~B} 2+0.0878 \mathrm{C}^{2}
$$

Table 4. Analysis of ANOVA for hairiness index (H) for 40 Ne yarn.

\begin{tabular}{llllll}
\hline \multicolumn{2}{l}{ Response 1: Hairiness of 40 Ne yarn and suggested ANOVA for the quadratic model } & & \\
\hline Source & Sum of Squares & df & Mean Square & F-value & p-value \\
\hline Model & 2.05 & 9 & 0.2277 & 80.79 & $<0.0001$ \\
A-Apron hole diameter & 0.0288 & 1 & 0.0288 & 10.22 & 0.0151 \\
B-Suction pressure & 0.1012 & 1 & 0.1012 & 35.92 & 0.0005 \\
C-Widthwise hole distance & 1.11 & 1 & 1.11 & 393.83 & $<0.0001$ \\
AB & 0.0002 & 1 & 0.0002 & 0.0798 & 0.7857 \\
AC & 0.0462 & 1 & 0.0462 & 16.40 & 0.0049 \\
BC & 0.0156 & 1 & 0.0156 & 5.54 & 0.0508 \\
A $^{2}$ & 0.3609 & 1 & 0.3609 & 128.03 & $<0.0001$ \\
$B^{2}$ & 0.2907 & 1 & 0.2907 & 103.13 & $<0.0001$ \\
$C^{2}$ & 0.0324 & 1 & 0.0324 & 11.50 & 0.0116 \\
Residual & 0.0197 & 7 & 0.0028 & & 0.4371 \\
Lack of Fit & 0.0091 & 3 & 0.0030 & 1.13 & Not significant \\
Pure Error & 0.0107 & 4 & 0.0027 & & \\
Cor Total & 2.07 & 16 & & & \\
\hline
\end{tabular}




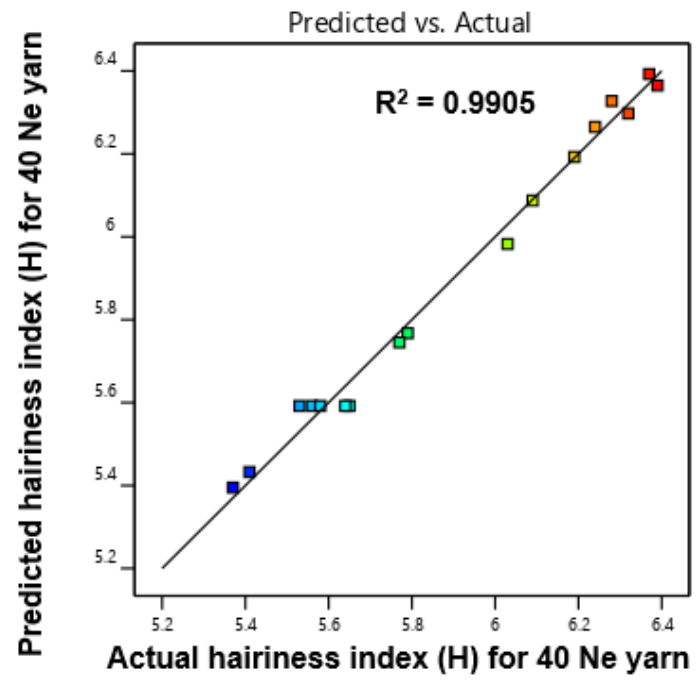

Figure 4. Relationship between actual and predicted values for hairiness of 40 Ne yarn.
As shown in Figure 5 the best-fitted model for hairiness of $40 \mathrm{Ne}$ was a quadratic, with $\mathrm{R}^{2}$ of 0.9905 . This suggests that the analyzed factor explains $99.05 \%$ of the hairiness for 40 $\mathrm{Ne}$ yarn and that the model could not explain only $0.95 \%$ of the variation of yarn hairiness. Therefore, a strong correlation is achieved between predicted and actual for the hairiness of $40 \mathrm{Ne}$ yarn.

Figure 5 shows that apron hole diameter, suction pressure, and widthwise hole distance have a significant effect on the hairiness of $40 \mathrm{Ne}$ yarn. The hairiness of $40 \mathrm{Ne}$ yarn was decreased as both hole diameter and suction pressure were at the center level. So far, as the hole distance increases hairiness of $40 \mathrm{Ne}$ yarn was increased. Therefore, it is concluded that lower hairiness was obtained at a $10 \mathrm{~mm}$ widthwise hole distance due to better condensation of the edge fibers.

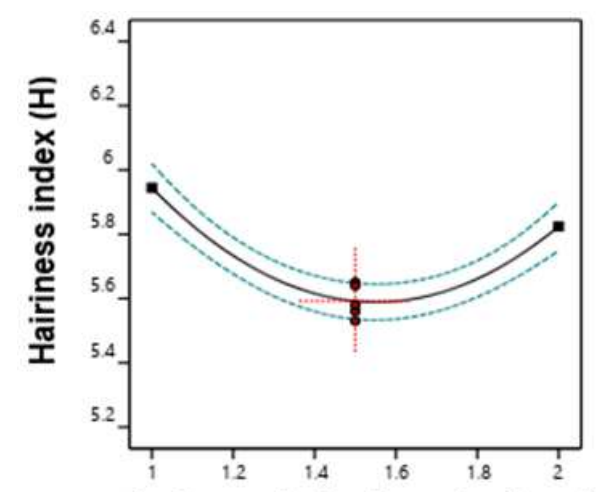

A: Apron hole diameter $(\mathrm{mm})$

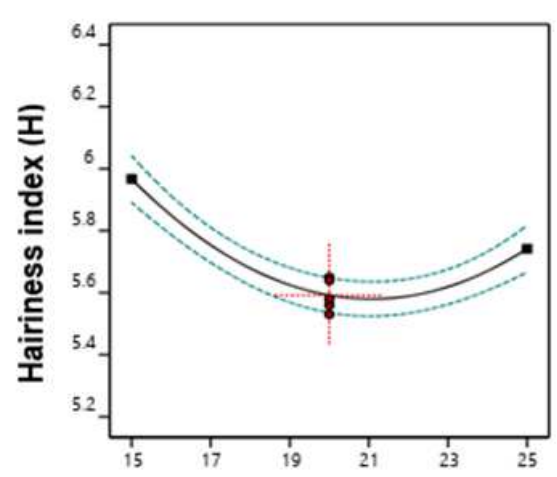

B: Suction air pressure (mbar)

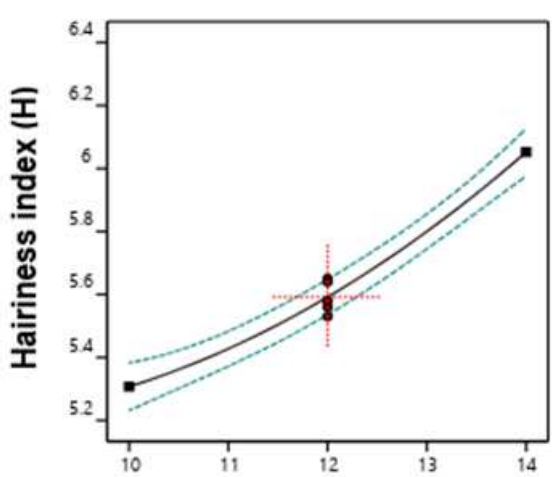

C: Widthwise hole distance $(\mathrm{mm})$

Figure 5. Effect of hole diameter, suction pressure, and hole distance on the hairiness of $40 \mathrm{Ne}$.

Figure 6 (a) shows that the minimum hairiness obtained was 5.53 when $1.5 \mathrm{~mm}$ hole diameter and 20 mbar suction pressure were used at a constant hole distance of $12 \mathrm{~mm}$. But, the interaction effects of the apron hole diameter and suction air pressure at a constant widthwise hole distance of $12 \mathrm{~mm}$ have no significant effect on the hairiness of the 40 Ne yarn.

Figure 6 (b) shows the interaction effects of apron hole diameter and widthwise hole distance on the hairiness of 40 $\mathrm{Ne}$ yarn at the center level of suction pressure (20 mbar). It was observed that the hairiness was decreased when the widthwise hole distance was at a low level and the apron hole diameter was at the center level. Thus, the result in Table 3 shows the minimum hairiness for $40 \mathrm{Ne}$ yarn was found to be 5.41 at a constant suction pressure of 20 mbar as the hole diameter was $2 \mathrm{~mm}$ and the widthwise hole distance was $10 \mathrm{~mm}$. This result was best when compared with all other interaction effects of apron hole diameter and widthwise hole distance at a constant suction pressure of 20 mbar as shown in Table 3. This is due to better binding and condensation of the edge fibers in the drafted ribbon because suction pressure and reduction in spinning triangles reduce yarn hairiness [19].

The interaction effect $\mathrm{BC}$ in Figure 6 (c) shows that the hairiness of $40 \mathrm{Ne}$ yarn was decreased as the suction pressure increases with a decrease in hole distance. The result in Table 3 proves that the hairiness was found to be 5.37 as suction pressure was 25 mbar and hole distance was $10 \mathrm{~mm}$ at a constant apron hole diameter of $1.5 \mathrm{~mm}$. Thus, it can be concluded that increasing the suction pressure to the optimum level reduces yarn hairiness significantly because the edge fibers were sucked through the air suction and the fibers are condensed to the yarn body [12, 19, 32-34]. 

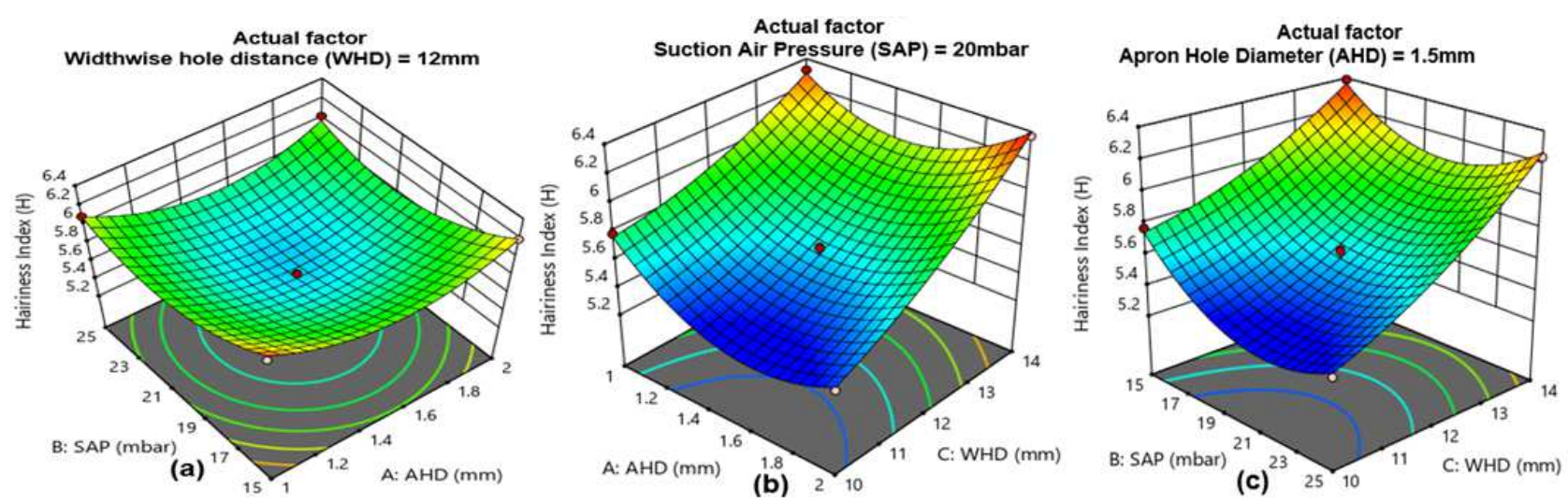

\section{Apron Hole Diameter (AHD) : Suction Air Pressure (SAP) : Widthwise hole distance (WHD)}

Figure 6. Factor interaction effect with a 3D Surface graph for hairiness of 40 Ne yarn.

\subsubsection{Tenacity (cN/tex)}

Analysis of ANOVA in Table 5 shows that the model Fvalue attained was 35.36 implies the model is significant. In this study, the suction air pressure (B), widthwise hole distance $(C)$, interaction effect $\mathrm{BC}$, and quadratic term $\left(\mathrm{A}^{2}\right.$ and $B^{2}$ ) are significant effects on the tenacity of $40 \mathrm{Ne}$ yarn. But, apron hole diameter $(A)$, quadratic hole distance $\left(C^{2}\right)$ and interaction $\mathrm{AB}$ and $\mathrm{AC}$ are not significant terms. Therefore, from the result, it can be concluded that as suction pressure increases to center level tenacity of $40 \mathrm{Ne}$ yarn increases significantly because the fibers are condensed before twist (Mageshkumar and Ramachandran, 2012, Ma et al., 2014, Chakrabortty et al., 2020). As a result of suction pressure, the reduction in structure of the spinning triangle causes small differences in the path followed by edge fibers to integrate into yarn body enables better utilization of the fibers increases yarn tenacity [35].

The regression model of $40 \mathrm{Ne}$ yarn is given in Equation (2). The model shows that the suction pressure (B) has a positive correlation with the tenacity of $40 \mathrm{Ne}$ yarn. However, widthwise hole distance $(\mathrm{C})$, interaction effect $\mathrm{BC}$ and quadratic term $\left(\mathrm{A}^{2}\right.$ and $\mathrm{B}^{2}$ ) have a negative correlation with the tenacity of $40 \mathrm{Ne}$ yarn. Widthwise hole distance (C) had the highest F-value of 202.71 implying that it had the most significant influence on the tenacity of $40 \mathrm{Ne}$ yarn. Therefore, from the result, it can be concluded that as the suction pressure increases to an optimum level with the decrease in widthwise hole distance the tenacity of $40 \mathrm{Ne}$ yarn increases significantly.

Tenacity $(\mathrm{cN} /$ tex $)=+13.43+0.8913 \mathrm{~B}-2.98 \mathrm{C}-0.9122 \mathrm{BC}-$

$$
2 \mathrm{~A}^{2}-1.61 \mathrm{~B}^{2}
$$

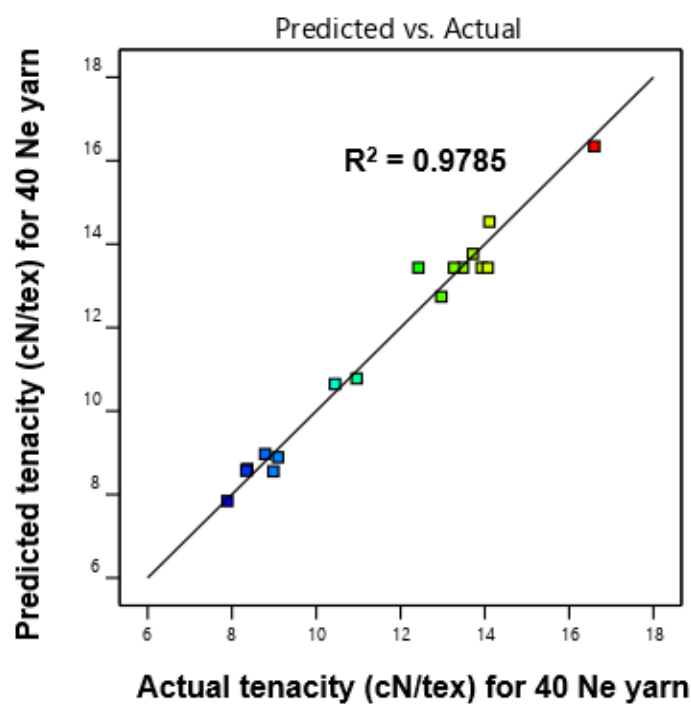

Figure 7. Relationship between actual and predicted tenacity for $40 \mathrm{Ne}$ yarn.

The best-fitted model for the tenacity of $40 \mathrm{Ne}$ yarn was a quadratic model, with $\mathrm{R}^{2}$ value of 0.9785 as shown in Figure 7. This suggests that the analyzed factor explains $97.85 \%$ of the tenacity for $40 \mathrm{Ne}$ yarn that the model could not explain only $2.15 \%$ variation. Therefore, a good agreement is achieved between the predicted and actual tenacity for $40 \mathrm{Ne}$ yarn. Thus, a second-order regression model is developed to predict the tenacity of yarn.

Moreover, the predicted $\mathrm{R}^{2}$ of 0.8714 is in reasonable agreement with the adjusted $\mathrm{R}^{2}$ of 0.9508 and the difference is less than 0.2 . In this study, the ratio of 18.751 on the fit statistics indicates an adequate signal is desirable.

Table 5. Analysis of ANOVA for the tenacity of 40 Ne yarn.

\begin{tabular}{lllllll}
\hline Response 2: Tenacity of 40 Ne yarn and suggested ANOVA for the quadratic model & & & \\
\hline Source & 111.27 & 9 & 12.36 & 35.38 & $<0.0001$ & Significant \\
Model & 0.0017 & 1 & 0.0017 & 0.0049 & 0.9462 & \\
A-Apron hole diameter & 6.35 & 1 & 6.35 & 18.18 & 0.0037 & \\
B-Suction pressure & 70.85 & 1 & 70.85 & 202.71 & $<0.0001$ & \\
C-Widthwise hole distance & 0.0111 & 1 & 0.0111 & 0.0318 & 0.8634 & \\
AB & 0.5491 & 1 & 0.5491 & 1.57 & 0.2503 & \\
\hline
\end{tabular}




\begin{tabular}{|c|c|c|c|c|c|c|}
\hline $\mathrm{AC}$ & 3.33 & 1 & 3.33 & 9.52 & 0.0177 & \\
\hline $\mathrm{BC}$ & 16.86 & 1 & 16.86 & 48.25 & 0.0002 & \\
\hline $\mathrm{A}^{2}$ & 10.92 & 1 & 10.92 & 31.25 & 0.0008 & \\
\hline $\mathrm{B}^{2}$ & 0.2786 & 1 & 0.2786 & 0.7973 & 0.4016 & \\
\hline $\mathrm{C}^{2}$ & 2.45 & 7 & 0.3495 & & 0.4021 & \\
\hline Residual & 0.7481 & 3 & 0.2494 & 0.5873 & 0.6548 & Not significant \\
\hline Lack of Fit & 1.70 & 4 & 0.4246 & & & \\
\hline Pure Error & 113.72 & 16 & & & & \\
\hline Cor Total & 111.27 & 9 & 12.36 & 35.38 & $<0.0001$ & Significant \\
\hline
\end{tabular}

Figure 8 approves that apron hole diameter has no significant effect on the tenacity of $40 \mathrm{Ne}$ yarn. But, the suction pressure and hole distance have a significant effect on the tenacity of $40 \mathrm{Ne}$ yarn. The tenacity of yarn increases as suction pressure increases up to center level with the decrease in widthwise hole distance. The tenacity increases as the fiber bundles are condensed by suction so short fibers are integrated into the yarn body (Ma et al., 2014).

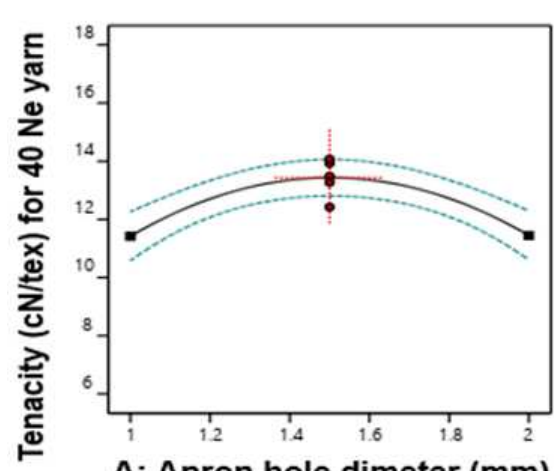

A: Apron hole dimeter $(\mathrm{mm})$

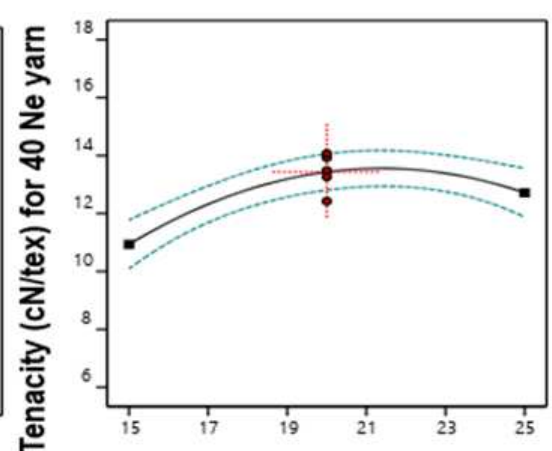

B: Suction air pressure (mbar)

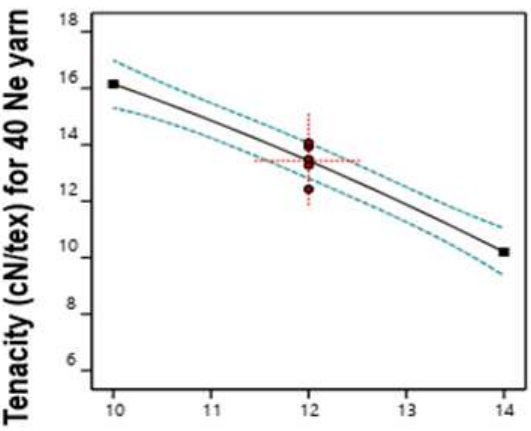

C:Widthwise hole distance $(\mathrm{mm})$

Figure 8. Effect of hole diameter, suction pressure, and hole distance on the tenacity of $40 \mathrm{Ne}$.

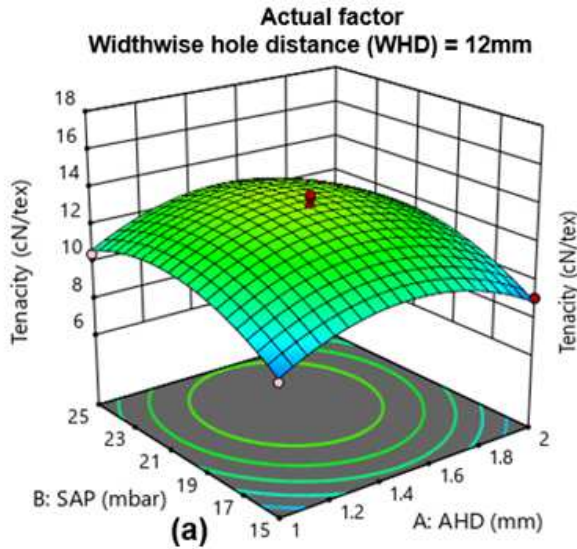

(a)

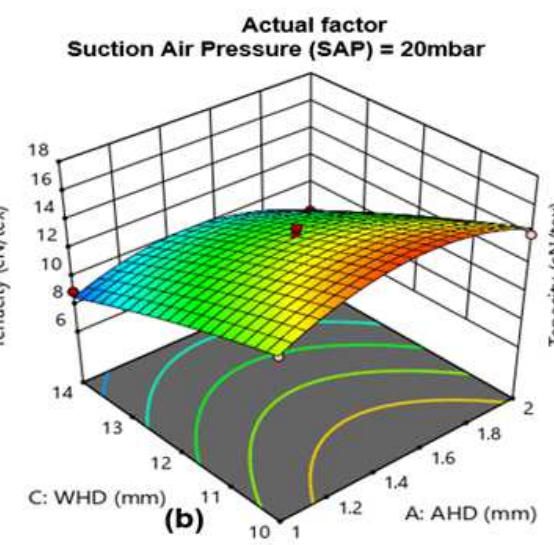

(b)

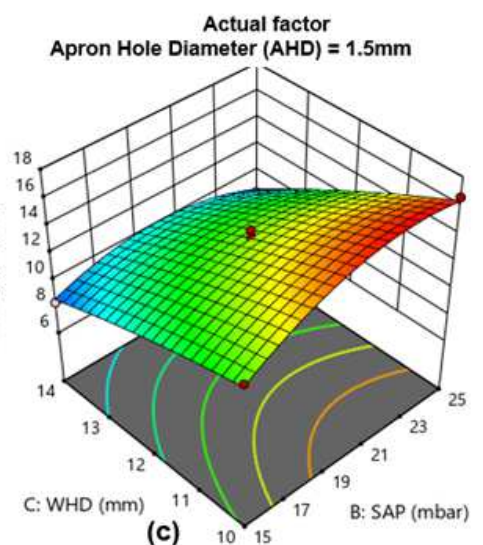

(c)

\section{Apron Hole Diameter (AHD) : Suction Air Pressure (SAP) : Widthwise hole distance (WHD)}

Figure 9. Factor interaction effect with the 3D surface graph for the tenacity of $40 \mathrm{Ne}$.

Figure 9 (a) shows that the maximum tenacity for $40 \mathrm{Ne}$ yarn was $14.069 \mathrm{cN} /$ tex as $1.5 \mathrm{~mm}$ apron hole diameter and 20 mbar suction were used at a constant hole distance of $12 \mathrm{~mm}$. the 3D response in Figure 9 (b) shows that the maximum tenacity for $40 \mathrm{Ne}$ was $14.107 \mathrm{cN} /$ tex as $2 \mathrm{~mm}$ apron hole diameter and $10 \mathrm{~mm}$ hole distance at a constant pressure of 20 mbar as shown in Table 3. At constant suction pressure of 20 mbar tenacity of $40 \mathrm{Ne}$ yarn was increased as apron hole diameter increases with decrease in hole distance [36, 37].

As shown in Figure 9 (c) the maximum tenacity for $40 \mathrm{Ne}$ yarn was $16.595 \mathrm{cN} /$ tex as $25 \mathrm{mbar}$ suction pressure and $10 \mathrm{~mm}$ widthwise hole distance was used at a constant hole diameter of $1.5 \mathrm{~mm}$. Therefore, from the experimental result, it can be concluded that the tenacity of $40 \mathrm{Ne}$ yarn increase with an increase in suction pressure to optimal. The suction condenses the fibers after emerging from the drafting to the nip line and sucks the protruding fibers resulting in the long fibers twisted that contributes to yarn strength (Chakrabortty et al., 2020).

\subsubsection{Nep $(+200 \% / \mathrm{km})$}

The analysis of ANOVA as shown in Table 6 shows the model F-value obtained in the present study was 1.44 implies the model is not significant. In this study, there are no 
significant model terms meaning apron hole diameter, suction pressure, and hole distance have not significant effect on nep $(+200 \% / \mathrm{km})$ for $40 \mathrm{Ne}$ yarn. The lack of fit F-value of 2.87 suggests the lack of fit is not significant relative to the pure error. The correlation coefficient $\left(R^{2}\right)$ between the experimental and predicted nep $(+200 \% / \mathrm{km})$ was 0.6488 .
This suggests that the analyzed factor explains $64.88 \%$ of nep $(+200 \% / \mathrm{km})$ for $40 \mathrm{Ne}$ yarn and that the model could not explain $35.12 \%$ of the variation. Therefore, a poor correlation has arisen between the predicted and actual value of the nep $(+200 \% / \mathrm{km})$ for $40 \mathrm{Ne}$ yarn. Thus, the model was not fit the response because the model is no significant effect on nep.

Table 6. Analysis of ANOVA for nep $(+200 \% / \mathrm{km})$ for 40 Ne yarn.

\begin{tabular}{|c|c|c|c|c|c|c|}
\hline Source & Sum of Squares & df & Mean Square & F-value & p-value & \\
\hline Model & $5.323 \mathrm{E}+06$ & 9 & $5.914 \mathrm{E}+05$ & 1.44 & 0.3235 & Not significant \\
\hline A-Apron hole diameter & $3.276 \mathrm{E}+05$ & 1 & $3.276 \mathrm{E}+05$ & 0.7961 & 0.4019 & \\
\hline B-Suction air pressure & $3.046 \mathrm{E}+05$ & 1 & $3.046 \mathrm{E}+05$ & 0.7401 & 0.4181 & \\
\hline C-Widthwise hole distance & $1.876 \mathrm{E}+06$ & 1 & $1.876 \mathrm{E}+06$ & 4.56 & 0.0702 & \\
\hline $\mathrm{AB}$ & $4.122 \mathrm{E}+05$ & 1 & $4.122 \mathrm{E}+05$ & 1.00 & 0.3503 & \\
\hline $\mathrm{AC}$ & 53130.25 & 1 & 53130.25 & 0.1291 & 0.7300 & \\
\hline $\mathrm{A}^{2}$ & $1.308 \mathrm{E}+06$ & 1 & $1.308 \mathrm{E}+06$ & 3.18 & 0.1178 & \\
\hline $\mathrm{B}^{2}$ & $4.598 \mathrm{E}+05$ & 1 & $4.598 \mathrm{E}+05$ & 1.12 & 0.3256 & \\
\hline $\mathrm{C}^{2}$ & $2.419 \mathrm{E}+05$ & 1 & $2.419 \mathrm{E}+05$ & 0.5878 & 0.4683 & \\
\hline Residual & $2.881 \mathrm{E}+06$ & 7 & $4.116 \mathrm{E}+05$ & & & \\
\hline Lack of Fit & $1.967 \mathrm{E}+06$ & 3 & $6.555 \mathrm{E}+05$ & 2.87 & 0.1675 & Not significant \\
\hline Pure Error & $9.144 \mathrm{E}+05$ & 4 & $2.286 \mathrm{E}+05$ & & & \\
\hline Cor Total & $8.204 \mathrm{E}+06$ & 16 & & & & \\
\hline
\end{tabular}

\subsubsection{Thin Place $(-50 \% / \mathrm{km})$}

The analysis of ANOVA in Table 7 shows that the model Fvalue obtained was 17.57 implies the model is significant. In this study, the suction pressure (B), widthwise hole distance (C), and quadratic widthwise hole distance $\left(\mathrm{C}^{2}\right)$ are significant effects on thin place $(-50 \% / \mathrm{km})$ for $40 \mathrm{Ne}$ yarn. However, the apron hole diameter $(\mathrm{A})$, all interactive effects $\mathrm{AB}, \mathrm{AC}$, and $\mathrm{BC}$ as well as quadratic term hole diameter $\left(\mathrm{A}^{2}\right)$ and suction pressure $\left(\mathrm{B}^{2}\right)$ are not significant model terms. The lack of fit $\mathrm{F}$ value of 0.69 showed the lack of fit is not significant relative to the pure error. There is a $60.50 \%$ chance that a lack of fit Fvalue this large could occur due to noise.

A quadratic model for the thin place $(-50 \% / \mathrm{km})$ was given in Equation (3). The regression model shows that linear widthwise hole distance has a high positive correlation with the thin place. The hole distance (C) had the highest F-value of 126.97 implying that it had the most significant influence on thin place $(-50 \% / \mathrm{km})$ for $40 \mathrm{Ne}$ yarn. As shown in Equation (3) the linear effects of suction pressure have a negative correlation with the thin place. Thus, the model predicts that as suction pressure increases the thin place ($50 \% / \mathrm{km})$ decreases.

Thin place $(-50 \% / \mathrm{km})=+311-18.87 \mathrm{~B}+78 \mathrm{C}-38.87 \mathrm{C}^{2}$

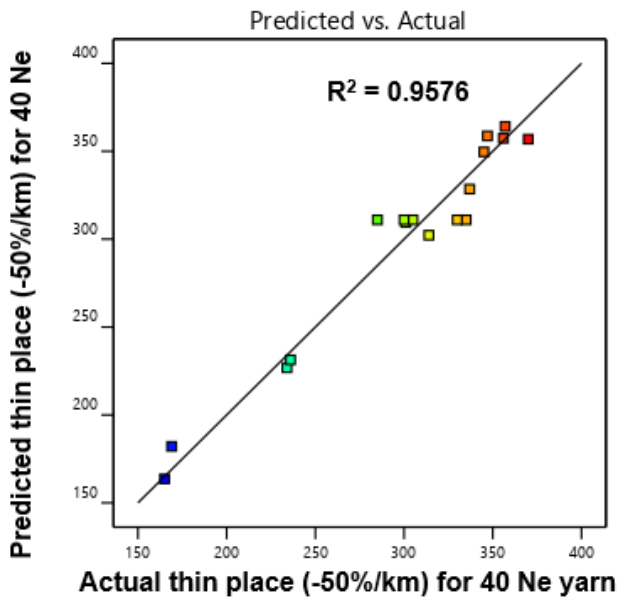

Figure 10. Relationship between actual and predicted thin place for $40 \mathrm{Ne}$ yarn.

The best-fitted model for the thin place $(-50 \% / \mathrm{km})$ of 40 $\mathrm{Ne}$ yarn was a quadratic model, with $\mathrm{R}^{2}$ value of 0.9576 as shown in Figure 10. This suggests that the analyzed factor explains $95.76 \%$ of the thin place $(-50 \% / \mathrm{km})$ for $40 \mathrm{Ne}$ yarn and that the model could not explain only $4.24 \%$ of the variation of thin place $(-50 \% / \mathrm{km})$. Therefore, a strong correlation was achieved between the predicted and actual thin place $(-50 \% / \mathrm{km})$ yarn to predict.

Table 7. Analysis of ANOVA for the thin place $(-50 \% / \mathrm{km})$ of 40 Ne yarn.

\begin{tabular}{llllll}
\hline \multicolumn{2}{l}{ Response 4: Thin place of 40} & Ne yarn and suggested ANOVA for the quadratic model & \\
\hline Source & Sum of Squares & df & Mean Square & F-value & p-value \\
\hline Model & 60603.22 & 9 & 6733.69 & 0.0005 \\
A-Apron hole diameter & 703.13 & 1 & 703.13 & 17.57 & 1.83 \\
B-Suction pressure & 2850.13 & 1 & 2850.13 & 7.44 & 0.2177 \\
C-Widthwise hole distance & 48672.00 & 1 & 48672.0 & 126.97 & 0.0295 \\
AB & 132.25 & 1 & 132.25 & 0.3450 & 0.5754 \\
AC & 676.00 & 1 & 676.00 & 1.76 & 0.2258 \\
\hline
\end{tabular}




\begin{tabular}{llllll}
\hline \multicolumn{2}{l}{ Response 4: Thin place of 40 Ne yarn and suggested ANOVA for the quadratic model } & & \\
\hline Source & Sum of Squares & df & Mean Square & F-value & p-value \\
\hline BC & 900.00 & 1 & 900.00 & 2.35 & 0.1693 \\
$\mathrm{~A}^{2}$ & 453.22 & 1 & 453.22 & 1.18 & 0.3129 \\
$\mathrm{~B}^{2}$ & 47.96 & 1 & 47.96 & 0.1251 & 0.7340 \\
$\mathrm{C}^{2}$ & 6363.22 & 1 & 6363.22 & 16.60 & 0.0047 \\
Residual & 2683.25 & 7 & 383.32 & & 0.6050 \\
Lack of Fit & 913.25 & 3 & 304.42 & 0.6879 & Not significant \\
Pure Error & 1770.00 & 4 & 442.50 & & \\
Cor Total & 63286.47 & 16 & & & \\
\hline
\end{tabular}

Figure 11 shows apron hole diameter has no significant effect on thin place of $40 \mathrm{Ne}$ yarn. However, the suction pressure and widthwise hole distance have a significant effect on the thin place $(-50 \% / \mathrm{km})$ of $40 \mathrm{Ne}$ yarn. Therefore, from the result, it can be concluded that the thin place of $40 \mathrm{Ne}$ yarn was decreased as suction pressure increases. Moreover, thin place $(-50 \% / \mathrm{km})$ for $40 \mathrm{Ne}$ yarn decreases with a decrease in widthwise hole distance.
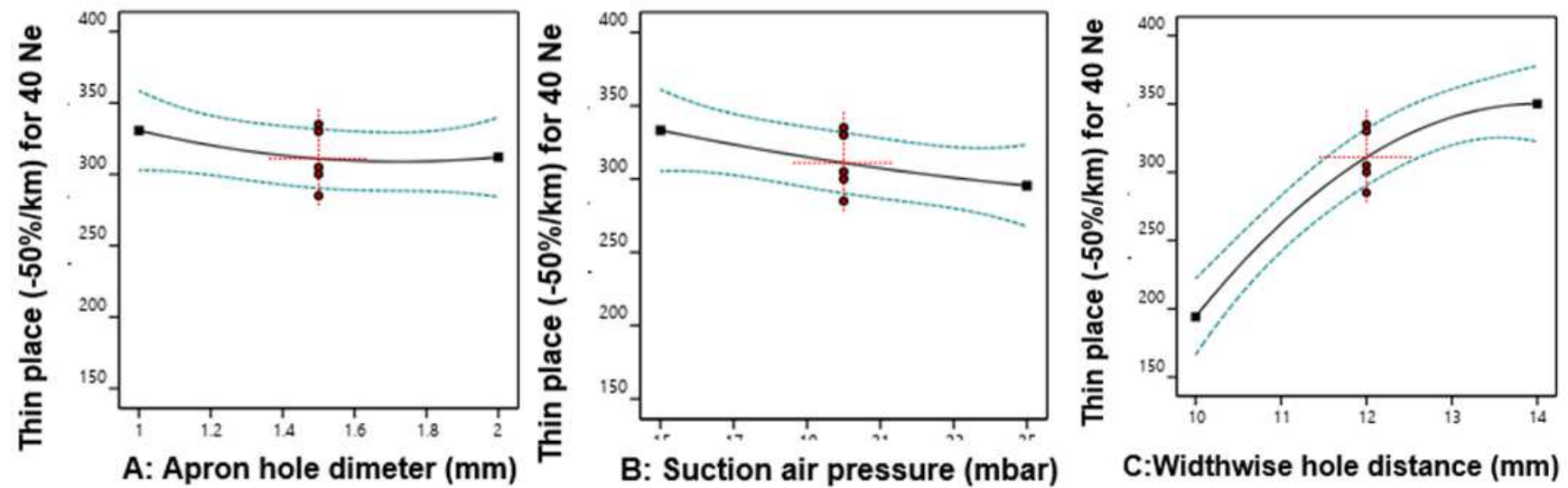

Figure 11. Effect of apron hole diameter, suction pressure, and widthwise hole distance on thin place (-50\%/km) of $40 \mathrm{Ne}$ yarn.

The 3D graph in Figure 12 reveals the interaction effects between apron hole diameter, suction pressure, and widthwise hole distance for the thin place $(-50 \% / \mathrm{km})$ for 40 Ne yarn. The all-factor interactions of apron hole diameter, suction air pressure, and widthwise hole distance in Figure 12 show no statistically significant effect on thin place ($50 \% / \mathrm{km})$ of $40 \mathrm{Ne}$ yarn.
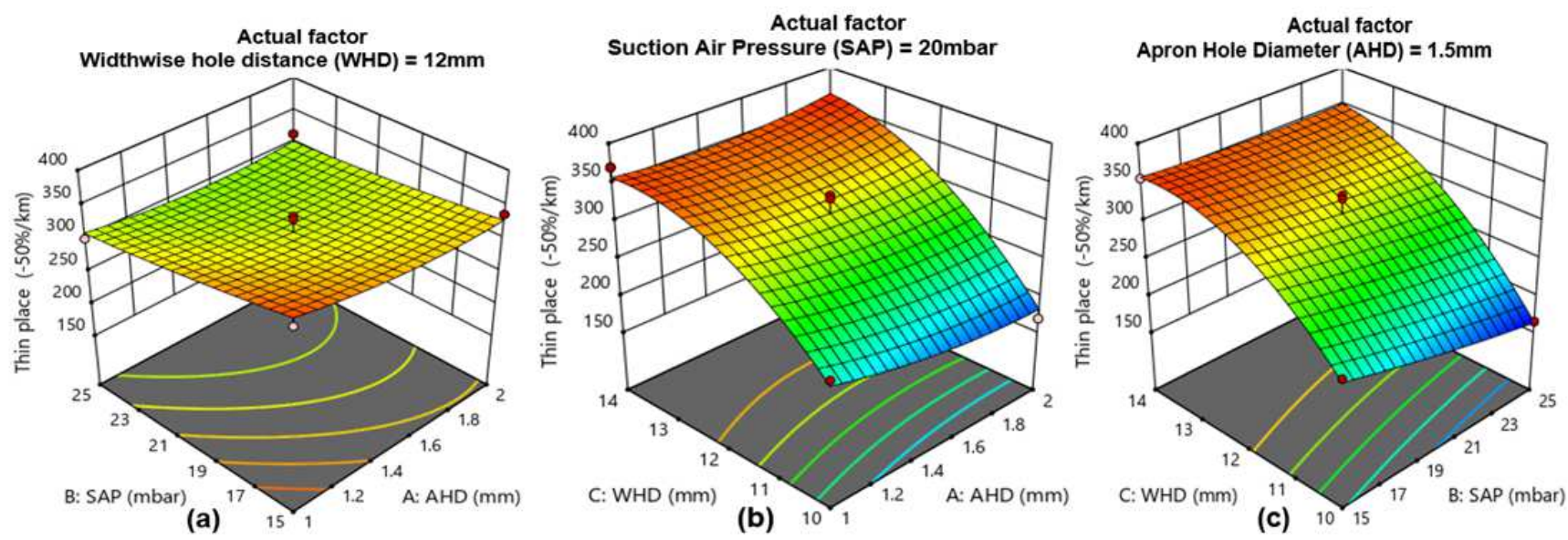

\section{Apron Hole Diameter (AHD) : Suction Air Pressure (SAP) : Widthwise hole distance (WHD)}

Figure 12. Factor interaction effect with the $3 D$ graph for a thin place (-50\%) of $40 \mathrm{Ne}$.

\subsubsection{Thick Place $(+50 \% / \mathrm{km})$}

Analysis of ANOVA in Table 8 shows the model F-value obtained was 36.9 implies the model is significant. In this study, apron hole diameter (A), suction pressure (B), hole distance $(\mathrm{C})$, and quadratic $\mathrm{A}^{2}$, and $\mathrm{B}^{2}$ are significant effects on thick place of $40 \mathrm{Ne}$ yarn. However, all interaction effects and quadratic hole distance $\left(\mathrm{C}^{2}\right)$ have no significant effect on thick place $(+50 \% / \mathrm{km})$. Lack of fit $\mathrm{F}$ value of 3.09 showed that lack of fit is not significant relative to pure error. 
Table 8. Analysis of ANOVA for the thick place ( $+50 \% / \mathrm{km})$ for 40 Ne yarn.

\begin{tabular}{llllll}
\hline \multicolumn{2}{l}{ Response 5: Thick place of 20 Ne yarn and suggested ANOVA for the quadratic model } & & \\
\hline Source & Sum of Squares & df & Mean Square & F-value & p-value \\
\hline Model & $9.599 \mathrm{E}+05$ & 9 & $1.067 \mathrm{E}+05$ & 36.90 & $<0.0001$ \\
A-Apron hole diameter & 20402.00 & 1 & 20402.00 & 7.06 & 0.0326 \\
B-Suction pressure & 35112.50 & 1 & 35112.50 & 12.15 & 0.0102 \\
C-Widthwise hole distance & $5.629 \mathrm{E}+05$ & 1 & $5.629 \mathrm{E}+05$ & 194.7 & $<0.0001$ \\
$\mathrm{AB}$ & 729.00 & 1 & 729.00 & 0.252 & 0.6309 \\
$\mathrm{AC}$ & 3025.00 & 1 & 3025.00 & 1.05 & 0.3403 \\
$\mathrm{BC}$ & 36.00 & 1 & 36.00 & 0.012 & 0.9143 \\
$\mathrm{~A}^{2}$ & $1.939 \mathrm{E}+05$ & 1 & $1.939 \mathrm{E}+05$ & 67.09 & $<0.0001$ \\
$\mathrm{~B}^{2}$ & $1.254 \mathrm{E}+05$ & 1 & $1.254 \mathrm{E}+05$ & 43.40 & 0.0003 \\
$\mathrm{C}^{2}$ & 146.57 & 1 & 146.57 & 0.050 & 0.8283 \\
Residual & 20231.80 & 7 & 2890.26 & & \\
Lack of Fit & 14129.00 & 3 & 4709.67 & 3.09 & 0.1523 \\
Pure Error & 6102.80 & 4 & 1525.70 & & not significant \\
Cor Total & $9.801 \mathrm{E}+05$ & 16 & & & \\
\hline
\end{tabular}

A quadratic model for the thick place $(+50 \% / \mathrm{km})$ of $40 \mathrm{Ne}$ was developed as shown in Equation (4) from ANOVA, in terms of coded parameters after rejecting the nonsignificant terms. The linear effects of hole diameter and suction pressure have a negative correlation with thick place. The positive coefficients for the linear, and quadratic term from the developed model in Equation (4) denotes a positive correlation, while the negative sign denotes an antagonistic relation on thick place $(+50 \% / \mathrm{km})$ for $40 \mathrm{Ne}$ yarn. However, widthwise hole distance (C) had the highest F-value of 194.74 shows that it had the most significant effect on thick place $(+50 \% / \mathrm{km})$ for $40 \mathrm{Ne}$ yarn as compared to hole diameter (A), and suction pressure (B). Thick place $(+50 \% / \mathrm{km})=+1509.8-50.5 \mathrm{~A}-66.25 \mathrm{~B}+$
$265.25 \mathrm{C}+214.6 \mathrm{~A}^{2}+172.6 \mathrm{~B}^{2}$

Hence, regression coefficient $\mathrm{R}^{2}$ of 0.9794 as shown in Figure 13 suggests that the analyzed factor explains $97.94 \%$ of thick place for $40 \mathrm{Ne}$ yarn and that the model could not explain only $2.06 \%$ of the variation. Therefore, a high correlation is achieved between predicted and actual value for the thick place $(+50 \% / \mathrm{km})$ of $40 \mathrm{Ne}$ yarn thus, the second-order regression model is confirmed to predict the thick place.

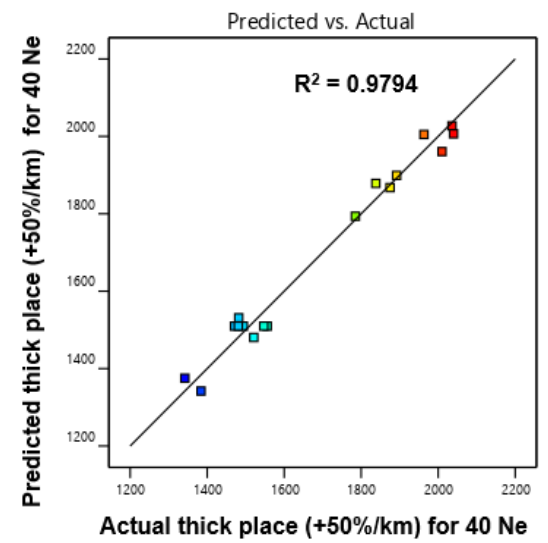

Figure 13. Relationship between actual and predicted thick place of $40 \mathrm{Ne}$ yarn.

Figure 14 confirms that apron hole diameter, suction pressure, and widthwise hole distance has a significant effect on the thick place $(+50 \% / \mathrm{km})$ of $40 \mathrm{Ne}$ yarn. Therefore, from the result, it can be concluded that the thick place for $40 \mathrm{Ne}$ yarn was decreased as the suction pressure increases up to center level (20 mbar). Therefore, in this study, widthwise hole distance has a more significant effect on the thick place $(+50 \%)$ of $40 \mathrm{Ne}$ yarn; thus, thick place decreases with a decrease in widthwise hole distance significantly.
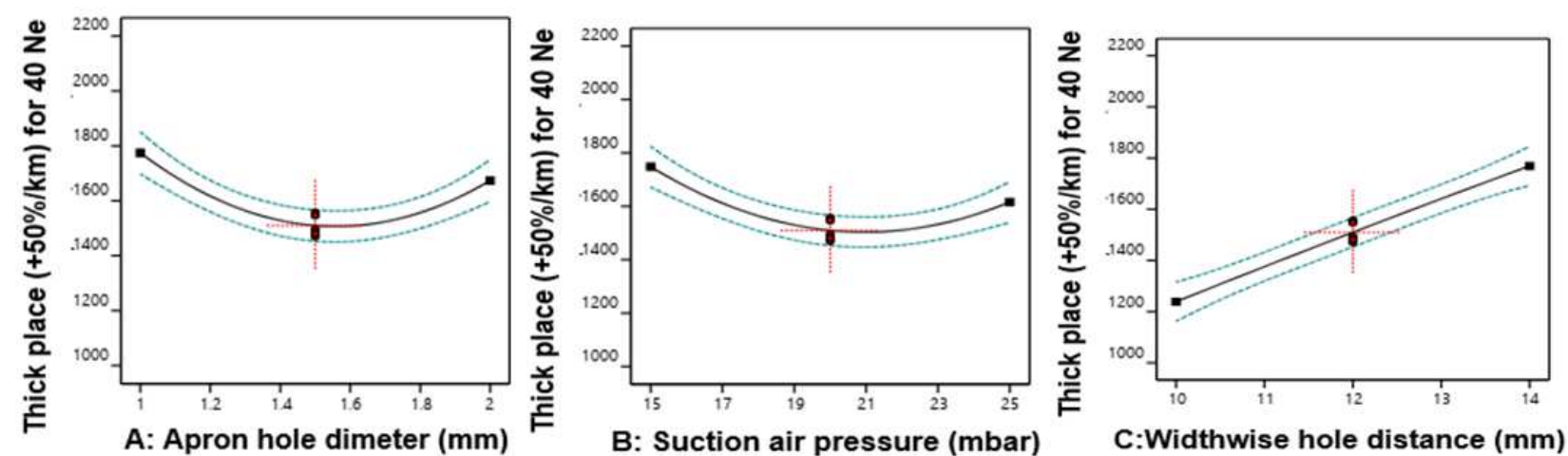

Figure 14. Effect of apron hole diameter, suction pressure, and widthwise hole distance on thick place $(+50 \% / \mathrm{km})$ in 40 Ne yarn. 
Figure 15 (a) shows that minimum thick place $(+50 \% / \mathrm{km})$ was 1471 when $1.5 \mathrm{~mm}$ apron hole diameter and $20 \mathrm{mbar}$ suction were used at a constant $12 \mathrm{~mm}$ widthwise hole distance as shown in Table 3 above. As revealed in Figure 15 (b) the minimum thick place $(+50 \% / \mathrm{km})$ was 1342 when 2 $\mathrm{mm}$ apron hole diameter and $10 \mathrm{~mm}$ widthwise hole distance was used at constant 20 mbar suction pressure. From Figure
15 (c) it can be observed that the minimum thick place $(+50 \% / \mathrm{km})$ was 1384 when $10 \mathrm{~mm}$ widthwise hole distance and 25 mbar suction pressure were used at a constant $1.5 \mathrm{~mm}$ apron hole diameter. Thus, the interaction effect of hole diameter, suction pressure, and widthwise hole distance $(\mathrm{AB}$, $\mathrm{AC}$, and $\mathrm{BC}$ ) has no significant effect on thick place $(+50 \% / \mathrm{km})$ of $40 \mathrm{Ne}$ yarn.

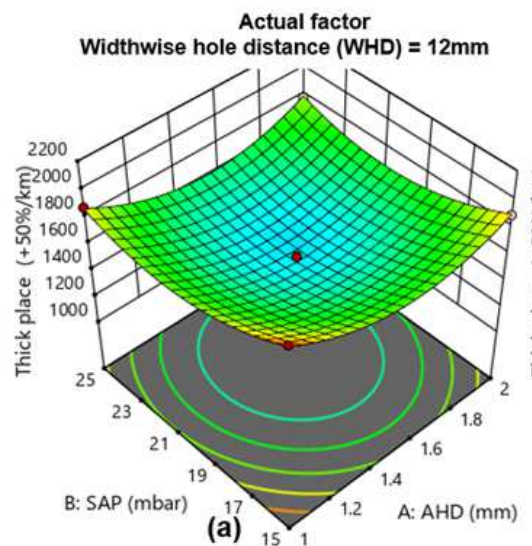

(a)

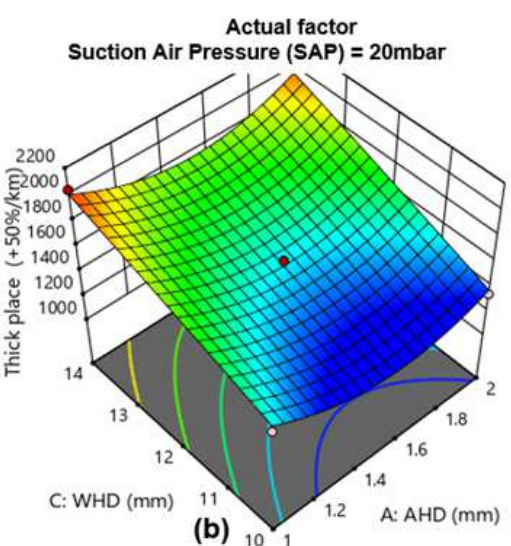

(b)

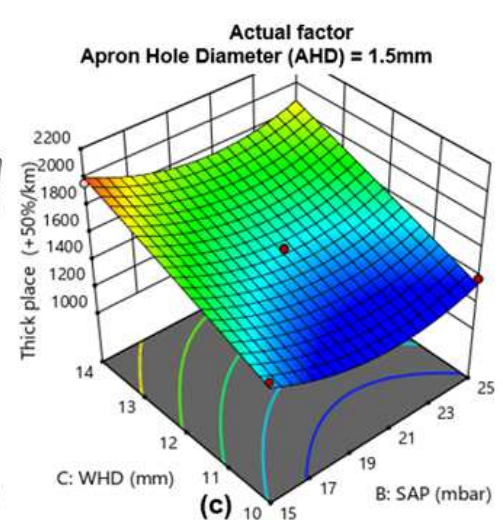

(c) 10

\section{Apron Hole Diameter (AHD) : Suction Air Pressure (SAP) : Widthwise hole distance (WHD)}

Figure 15. Factor interaction effect with $3 D$ for the thick place $(+50 \% / \mathrm{km})$ of $40 \mathrm{Ne}$ yarn.

\subsubsection{Optimized Solution of Apron Hole Diameter, Suction Pressure and Widthwise Hole Distance for Properties of 40 Ne Yarn}

Optimization was done by design expert software with the numerical optimization method. Thus, Table 9 shows the optimized solution of apron hole diameter, suction pressure, and widthwise hole distance for properties of $40 \mathrm{Ne}$ yarn. Thus, in this study 0.958 desirability shows that optimized solution for the given factor fits for the best result of the response.

Table 9. Optimized solution for 40 Ne yarn.

\begin{tabular}{|c|c|c|c|c|c|c|c|c|c|}
\hline $\begin{array}{l}\text { Apron hole } \\
\text { diameter (mm) }\end{array}$ & $\begin{array}{l}\text { Suction pressure } \\
\text { (mbar) }\end{array}$ & $\begin{array}{l}\text { Widthwise hole } \\
\text { distance }(\mathrm{mm})\end{array}$ & $\begin{array}{l}\text { Tenacity } \\
\text { (cN/tex) }\end{array}$ & $\begin{array}{l}\text { Hairiness } \\
\text { Index (H) }\end{array}$ & $\begin{array}{l}\text { Nep } \\
(+\mathbf{2 0 0} \% / \mathbf{k m})\end{array}$ & $\begin{array}{l}\text { Thin place } \\
(-50 \% / \mathrm{km})\end{array}$ & $\begin{array}{l}\text { Thick place } \\
(+50 \% / \mathbf{k m})\end{array}$ & Desirability & \\
\hline 1.580 & 23.910 & 10.000 & 16.595 & 5.313 & 2359.805 & 167.093 & 1284.753 & 0.958 & Selected \\
\hline
\end{tabular}

\subsection{Effect of Apron Hole Diameter, Suction Air Pressure, and Widthwise Hole Distance on the Properties of 20 Ne Ring Yarn}

Average yarn test results of $20 \mathrm{Ne}$ yarn spun on the modified G 35 ring were shown in Table 10.

Table 10. Average test results for 20 Ne yarn spun with modified $G 35$ ring with different combinations.

\begin{tabular}{|c|c|c|c|c|c|c|c|c|}
\hline & Factor 1 & Factor 2 & Factor 3 & Response 1 & Response 2 & Response 3 & Response 4 & Response 5 \\
\hline Run & $\begin{array}{l}\text { A: Apron hole } \\
\text { diameter }(\mathrm{mm})\end{array}$ & $\begin{array}{l}\text { B: Suction pressure } \\
\text { (mbar) }\end{array}$ & $\begin{array}{l}\text { C: Widthwise hole } \\
\text { distance }(\mathrm{mm})\end{array}$ & Tenacity & $\begin{array}{l}\text { Hairiness } \\
\text { index }(\mathbf{H})\end{array}$ & $\begin{array}{l}\text { Nep } \\
(+200 \% / \mathbf{k m})\end{array}$ & $\begin{array}{l}\text { Thin place } \\
(-50 \% / \mathrm{km})\end{array}$ & $\begin{array}{l}\text { Thick place } \\
(+50 \% / \mathbf{k m})\end{array}$ \\
\hline 1 & 1.5 & 20 & 12 & 15.307 & 7.84 & 953 & 44 & 594 \\
\hline 2 & 1.5 & 15 & 10 & 14.791 & 7.85 & 770 & 31 & 758 \\
\hline 3 & 1 & 20 & 10 & 15.142 & 7.915 & 821 & 49 & 715 \\
\hline 4 & 1.5 & 20 & 12 & 15.348 & 7.54 & 870 & 65 & 629 \\
\hline 5 & 1.5 & 25 & 10 & 18.282 & 7.06 & 1020 & 29 & 374 \\
\hline 6 & 2 & 15 & 12 & 13.58 & 8.18 & 913 & 32 & 640 \\
\hline 7 & 1 & 15 & 12 & 13.43 & 8.28 & 895 & 20 & 883 \\
\hline 8 & 2 & 20 & 10 & 15.327 & 7.48 & 1045 & 52 & 485 \\
\hline 9 & 1.5 & 20 & 12 & 14.838 & 7.58 & 998 & 38 & 643 \\
\hline 10 & 1 & 20 & 14 & 13.63 & 8.59 & 843 & 42 & 795 \\
\hline 11 & 1.5 & 15 & 14 & 14.086 & 8.48 & 785 & 81 & 769 \\
\hline 12 & 1.5 & 20 & 12 & 15.279 & 7.61 & 975 & 35 & 624 \\
\hline 13 & 1 & 25 & 12 & 16.713 & 7.95 & 783 & 46 & 595 \\
\hline
\end{tabular}




\begin{tabular}{|c|c|c|c|c|c|c|c|c|}
\hline & Factor 1 & Factor 2 & Factor 3 & Response 1 & Response 2 & Response 3 & Response 4 & Response 5 \\
\hline Run & $\begin{array}{l}\text { A: Apron hole } \\
\text { diameter (mm) }\end{array}$ & $\begin{array}{l}\text { B: Suction pressure } \\
\text { (mbar) }\end{array}$ & $\begin{array}{l}\text { C: Widthwise hole } \\
\text { distance }(\mathrm{mm})\end{array}$ & Tenacity & $\begin{array}{l}\text { Hairiness } \\
\text { index }(\mathrm{H})\end{array}$ & $\begin{array}{l}\text { Nep } \\
(+200 \% / \mathbf{k m})\end{array}$ & $\begin{array}{l}\text { Thin place } \\
(-50 \% / \mathbf{k m})\end{array}$ & $\begin{array}{l}\text { Thick place } \\
(+50 \% / \mathbf{k m})\end{array}$ \\
\hline 14 & 1.5 & 20 & 12 & 15.326 & 7.54 & 948 & 55 & 612 \\
\hline 15 & 2 & 25 & 12 & 16.593 & 7.19 & 813 & 37 & 385 \\
\hline 16 & 2 & 20 & 14 & 14.642 & 8.09 & 838 & 69 & 682 \\
\hline 17 & 1.5 & 25 & 14 & 15.984 & 7.93 & 840 & 28 & 520 \\
\hline
\end{tabular}

\subsubsection{Hairiness Index $(H)$}

The analysis of ANOVA in Table 11 shows that the model F-value obtained in the present study was 30.92 implies the model is significant. In this study, apron hole diameter (A), suction pressure (B), widthwise hole distance (C), interaction effects $(\mathrm{AB})$, and quadratic terms $\left(\mathrm{A}^{2}\right.$, and $\left.\mathrm{C}^{2}\right)$ have a significant effect on the hairiness of $20 \mathrm{Ne}$ yarn. The suction pressure had the highest F-value of 97.78 implies that it had the most significant effect on the hairiness of $20 \mathrm{Ne}$ yarn. However, interaction effect $\mathrm{AC}, \mathrm{BC}$, and quadratic suction pressure $\left(\mathrm{B}^{2}\right)$ has no significant effect on the hairiness of 20 $\mathrm{Ne}$ yarn since the p-values are greater than 0.05 .

Table 11. Analysis of ANOVA for hairiness of 20 Ne yarn.

\begin{tabular}{llllll}
\hline \multicolumn{2}{l}{ Response 1: Hairiness index for 20 Ne and suggested } & ANOVA for the quadratic model & & \\
\hline Source & Sum of Squares & df & Mean Square & F-value & p-value \\
\hline Model & 2.76 & 9 & 0.3066 & 30.92 & $<0.0001$ \\
A-Apron hole diameter & 0.4028 & 1 & 0.4028 & 40.62 & 0.0004 \\
B-Suction pressure & 0.8844 & 1 & 0.8844 & 89.20 & $<0.0001$ \\
C-Widthwise hole distance & 0.9695 & 1 & 0.9695 & 97.78 & $<0.0001$ \\
AB & 0.1089 & 1 & 0.1089 & 10.98 & 0.0129 \\
AC & 0.0011 & 1 & 0.0011 & 0.1065 & 0.7537 \\
BC & 0.0144 & 1 & 0.0144 & 1.45 & 0.2673 \\
$\mathrm{~A}^{2}$ & 0.2293 & 1 & 0.2293 & 23.13 & 0.0019 \\
$\mathrm{~B}^{2}$ & 0.0084 & 1 & 0.0084 & 0.8456 & 0.3884 \\
$\mathrm{C}^{2}$ & 0.1124 & 1 & 0.1124 & 11.33 & 0.0120 \\
Residual $_{\text {Lack of Fit }}$ & 0.0694 & 7 & 0.0099 & & 0.9319 \\
Pure Error & 0.0065 & 3 & 0.0022 & 0.1385 & not significant \\
Cor Total & 0.0629 & 4 & 0.0157 & & \\
\hline
\end{tabular}

For predicting hairiness of $20 \mathrm{Ne}$ yarn the regression model from the analyzed ANOVA and given in Equation (5). The linear main effects of hole diameter, suction pressure, and its interaction effects have a negative correlation with the hairiness index of $20 \mathrm{Ne}$ as shown in Equation (5). From the result and developed model, it can be concluded that the hairiness index for $20 \mathrm{Ne}$ yarn decreases significantly as the suction pressure and hole diameter increase. Thus, a model has been developed for predicting the yarn quality at various apron hole diameters, suction pressure, and widthwise hole in the modified G 35 ring.

$$
\text { Hairiness index }(\mathrm{H})=+7.62-0.224 \mathrm{~A}-0.332 \mathrm{~B}+0.348 \mathrm{C}-0.165 \mathrm{AB}+0.233 \mathrm{~A}^{2}+0.163 \mathrm{C}^{2}
$$

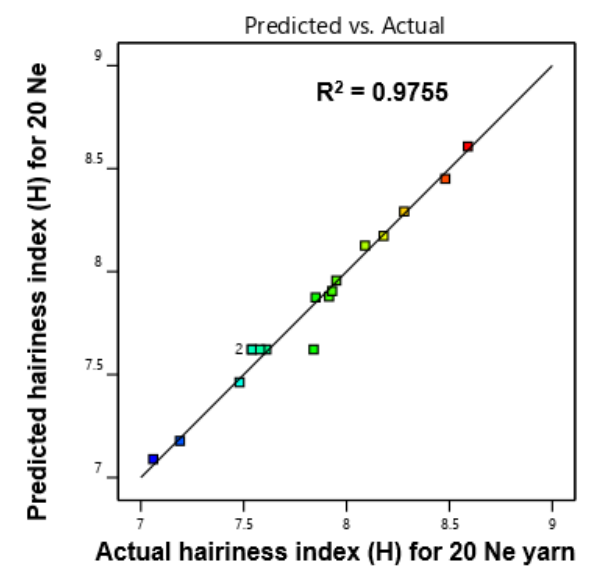

Figure 16. Relationship between actual and predicted hairiness of $20 \mathrm{Ne}$ yarn.

The best-fitted model for predicting the hairiness index of
$20 \mathrm{Ne}$ yarn was a quadratic model with $\mathrm{R}^{2}$ value of 0.9755 as shown in Figure 16. This suggests that the analyzed factors explain $97.55 \%$ of the $20 \mathrm{Ne}$ yarn hairiness and that the model could not explain only $2.45 \%$ of the variation of the yarn hairiness. Therefore, a strong correlation is achieved between the predicted and actual value for $20 \mathrm{Ne}$ yarn hairiness. Hence, second-order regression model is confirmed to predict the hairiness index of courser yarn.

Figure 17 shows that the apron hole diameter, suction air pressure, and the hole distance have a significant effect on the hairiness of $20 \mathrm{Ne}$ yarn. The hairiness index for $20 \mathrm{Ne}$ yarn was decreased as both apron hole diameter and suction pressure increases. However, as widthwise hole distance decreases hairiness index for $20 \mathrm{Ne}$ yarn was decreases. Hence, to suck the edge fibers during drafting the perforation of hole distance must meet with the drafted ribbon width. Therefore, from this study, it is concluded that lower hairiness was obtained at a $10 \mathrm{~mm}$ hole distance. 


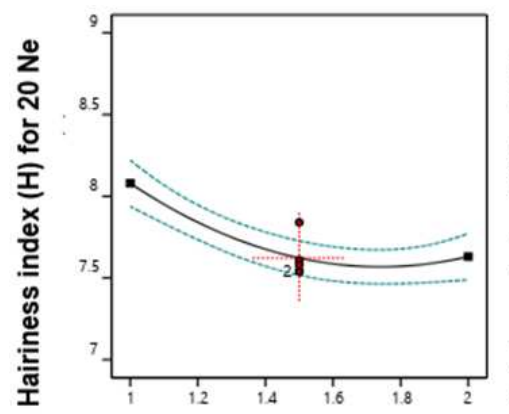

A: Apron hole dimeter (mm)

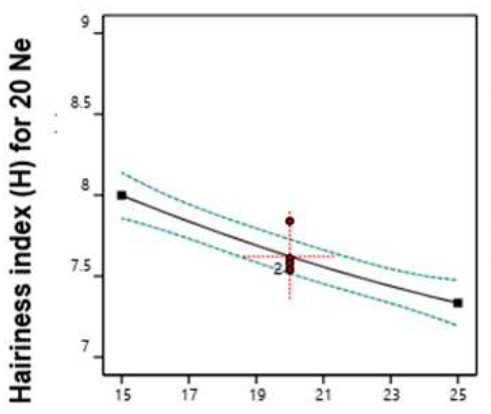

B: Suction air pressure (mbar)

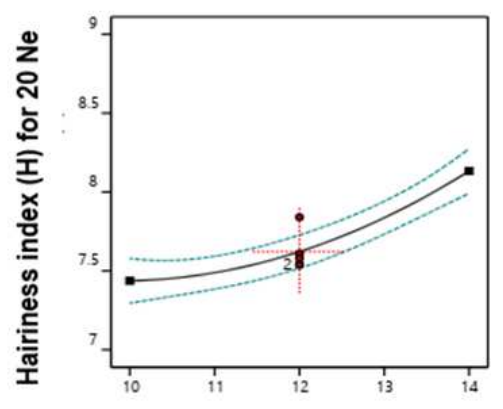

C:Widthwise hole distance $(\mathrm{mm})$

Figure 17. Effect of hole diameter, suction pressure, and hole distance on the hairiness of $20 \mathrm{Ne}$.

The 3D plot in Figure 18 (a) shows that minimum hairiness was found to be 7.19 as $2 \mathrm{~mm}$ hole diameter and 25 mbar suction pressure were used at a constant $12 \mathrm{~mm}$ hole distance as shown in Table 10 above. Furthermore, the 3D surface in Figure 18 (b) shows that the interaction effects between apron hole diameter and widthwise hole distance at a constant suction pressure of 20 mbar have no significant effect on the hairiness of the $20 \mathrm{Ne}$ yarn. Figure 18 (c) reveals that interaction effects between widthwise hole distance and suction pressure at a constant hole diameter of $1.5 \mathrm{~mm}$ have no significant effect on the hairiness of $20 \mathrm{Ne}$ yarn.
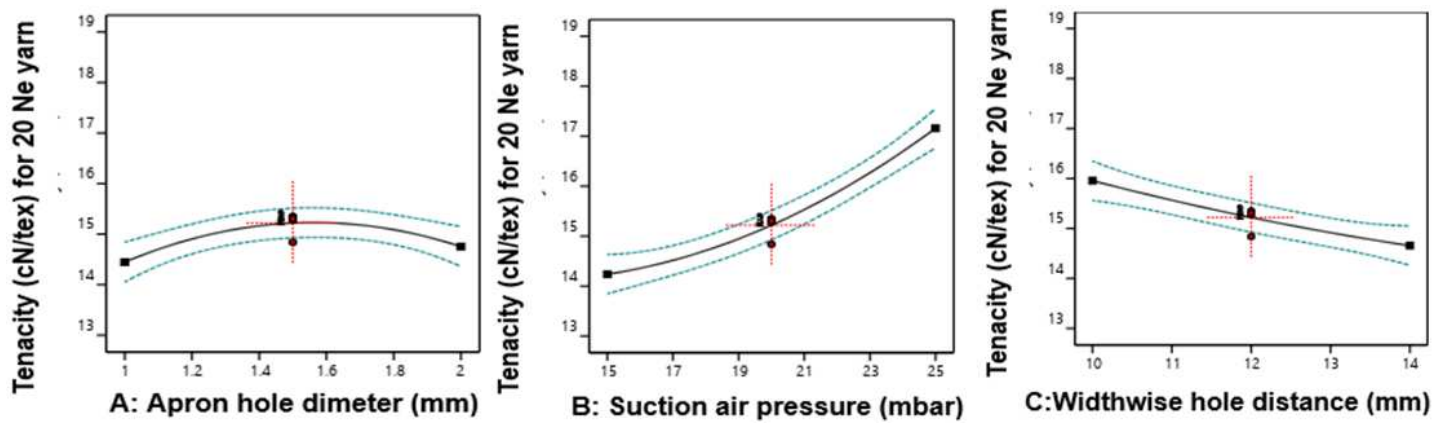

\section{Apron Hole Diameter (AHD) : Suction Air Pressure (SAP) : Widthwise hole distance (WHD)}

Figure 18. Factor interaction effect with a 3D Surface graph for hairiness of $20 \mathrm{Ne}$.

\subsubsection{Tenacity}

The analysis of the ANOVA in Table 12 shows that the model F-value obtained was 34.57 implies the model is significant. In this study, suction pressure (B), widthwise hole distance $(\mathrm{C})$, interaction effect $\mathrm{BC}$, and quadratic effects $\left(A^{2}\right.$, and $\left.B^{2}\right)$ are significant effects on the tenacity of $20 \mathrm{Ne}$ yarn. However, hole diameter (A), interaction effect $\mathrm{AB}, \mathrm{AC}$ and also quadratic effects of hole distance are not significant model terms. Therefore, from the result, it can be concluded that when the suction pressure increases tenacity of the yarn increases significantly.

For predicting yarn tenacity, the regression model from ANOVA, in terms of coded parameters after rejecting nonsignificant model terms is developed in Equation (6). The model shows that the linear term suction pressure (B) has a strong positive correlation with the tenacity of $20 \mathrm{Ne}$ yarn. Thus, the suction pressure had the highest F-value of 221.71 implies that it had the most significant influence on the hairiness of $20 \mathrm{Ne}$ yarn in comparison with hole diameter (A) and widthwise hole distance $(C)$. However, the liner term widthwise hole distance, interaction effects $\mathrm{BC}$ and $\mathrm{AC}$, as well as quadratic apron hole diameter $\left(\mathrm{A}^{2}\right)$ and suction pressure $\left(\mathrm{B}^{2}\right)$, has a negative correlation with tenacity. Therefore, from the result, it was observed that when suction pressure increases with a decrease in widthwise hole distance tenacity of $20 \mathrm{Ne}$ yarn increases significantly. Hence using the relation in Equation (6) the tenacity of yarn can be predicted by varying the hole diameter, suction pressure, and hole distance in a modified GN35 ring frame.

$$
\text { Tenacity }(\mathrm{cN} / \text { tex })=+15.22+1.46 \mathrm{~B}-0.65 \mathrm{C}-0.3982 \mathrm{BC}-0.6206 \mathrm{~A}^{2}-0.4799 \mathrm{~B}^{2}
$$

The best-fitted model for predicting the tenacity of yarn was a quadratic model, with $\mathrm{R}^{2}$ value of 0.9780 as shown in Figure 19. This suggests that the analyzed factor explains $97.80 \%$ of the tenacity of $20 \mathrm{Ne}$ yarn and that the model could not explain only $2.2 \%$ of the variation of yarn tenacity. Therefore, a good agreement is achieved between the predicted and actual tenacity. 


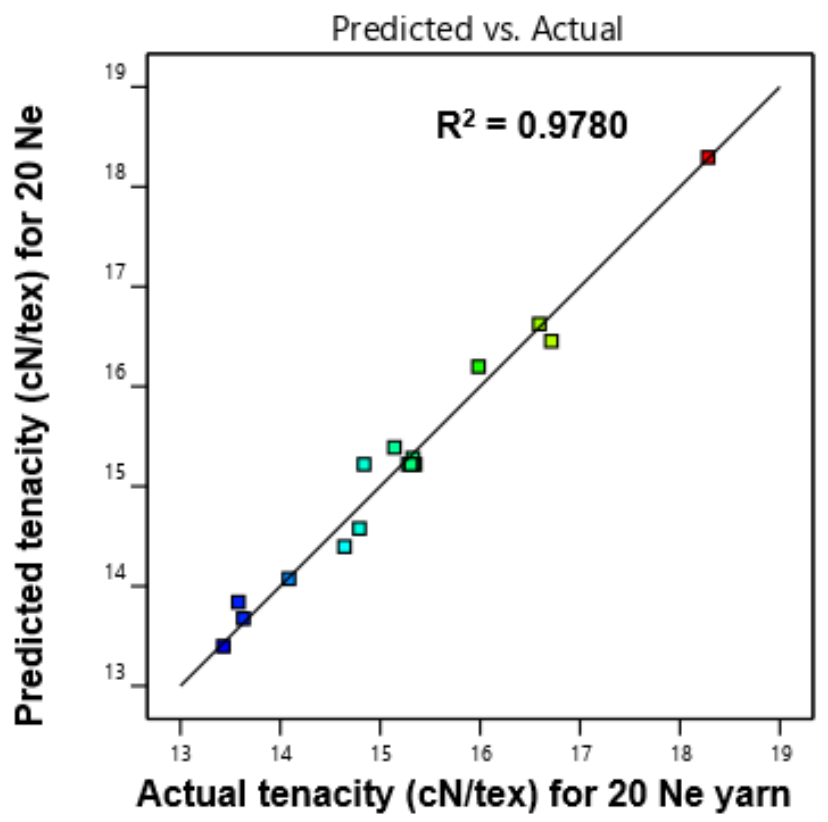

Figure 19. Relationship between actual and predicted tenacity for 20 Ne yarn.

Table 12. Analysis of ANOVA for the tenacity of 20 Ne yarn.

\begin{tabular}{lllllll}
\hline \multicolumn{2}{l}{ Response 2: Tenacity of 20 Ne yarn and suggested ANOVA for the quadratic model } & & \\
\hline Source & Sum of Squares & Df & Mean Square & F-value & p-value \\
\hline Model & 23.95 & 9 & 2.66 & 34.57 & $<0.0001$ & Significant \\
A-Hole diameter & 0.1882 & 1 & 0.1882 & 2.44 & 0.1619 \\
B-Suction Pressure & 17.07 & 1 & 17.07 & 221.71 & $<0.0001$ \\
C-Widthwise hole distance & 3.38 & 1 & 3.38 & 43.91 & 0.0003 \\
AB & 0.0182 & 1 & 0.0182 & 0.2367 & 0.6414 \\
AC & 0.1710 & 1 & 0.1710 & 2.22 & 0.1798 \\
BC & 0.6344 & 1 & 0.6344 & 8.24 & 0.0240 \\
$\mathrm{~A}^{2}$ & 1.62 & 1 & 1.62 & 21.06 & 0.0025 \\
$\mathrm{~B}^{2}$ & 0.9699 & 1 & 0.9699 & 12.60 & 0.0093 \\
$\mathrm{C}^{2}$ & 0.0313 & 1 & 0.0313 & 0.4064 & 0.5441 \\
Residual & 0.5389 & 7 & 0.0770 & & \\
Lack of Fit & 0.3543 & 3 & 0.1181 & 2.56 & 0.1930 \\
Pure Error & 0.1846 & 4 & 0.0461 & & \\
Cor Total & 24.49 & 16 & & & Not significant \\
\hline
\end{tabular}

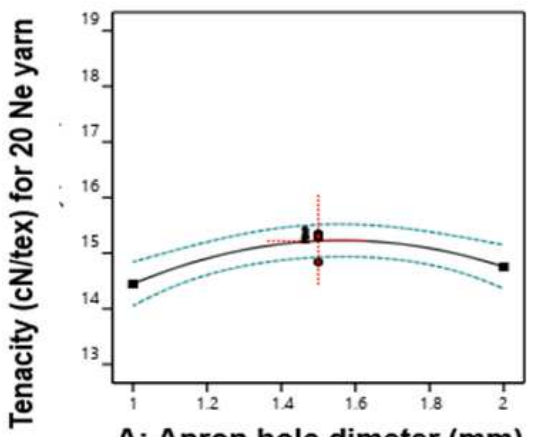

A: Apron hole dimeter ( $\mathrm{mm})$

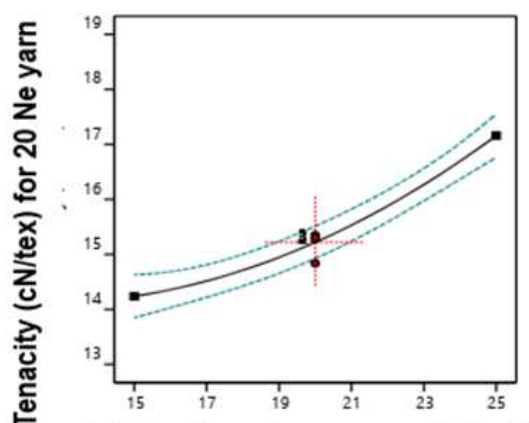

B: Suction air pressure (mbar)

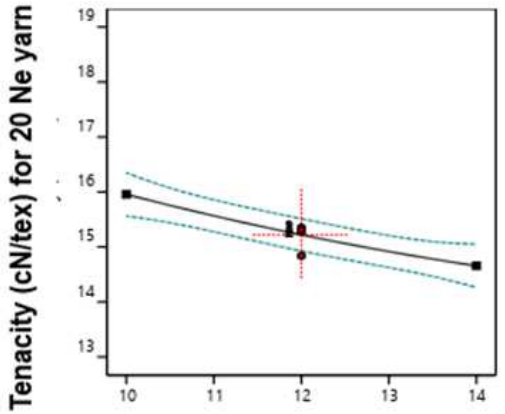

C:Widthwise hole distance (mm)

Figure 20. Effect of hole diameter, suction pressure, and hole distance on the tenacity of $20 \mathrm{Ne}$.

Figure 20 shows that apron hole diameter has no significant effect on the tenacity of $20 \mathrm{Ne}$ yarn. However, the suction pressure and hole distance have a significant effect on the tenacity of $20 \mathrm{Ne}$ yarn. The tenacity of yarn increases as suction increases with a decrease in hole distance.
Figure 21 (a) shows that the maximum tenacity for $20 \mathrm{Ne}$ yarn was $16.713 \mathrm{cN} /$ tex when $1 \mathrm{~mm}$ apron hole diameter and 25 mbar suction pressure were used at a constant hole distance of $12 \mathrm{~mm}$. Even though, the model interaction effects of hole diameter and suction pressure at $12 \mathrm{~mm}$ hole 
distance are not significant. As shown in Figure 21 (b) the maximum tenacity for $20 \mathrm{Ne}$ was $15.348 \mathrm{cN} /$ tex as $1.5 \mathrm{~mm}$ hole diameter and $12 \mathrm{~mm}$ hole distance was used at a constant suction pressure of 20 mbar. However, the interaction effect between apron hole diameter and widthwise distance has not significant.

Moreover, in Figure 21 (c) maximum tenacity for $20 \mathrm{Ne}$ yarn was $18.282 \mathrm{cN} /$ tex when 25 mbar suction pressure and $10 \mathrm{~mm}$ hole distance was used at a constant apron hole diameter of $1.5 \mathrm{~mm}$ as shown in Table 10 above. Tenacity was increased as hole distance decreases with an increase in suction pressure at a constant apron hole diameter of $1.5 \mathrm{~mm}$. The result shown in Figure 21 (c) was better as compared with all other combinations of the levels of variables. Therefore, from the experimental result, it can be concluded that the tenacity of $20 \mathrm{Ne}$ yarn increase with an increase in suction pressure.
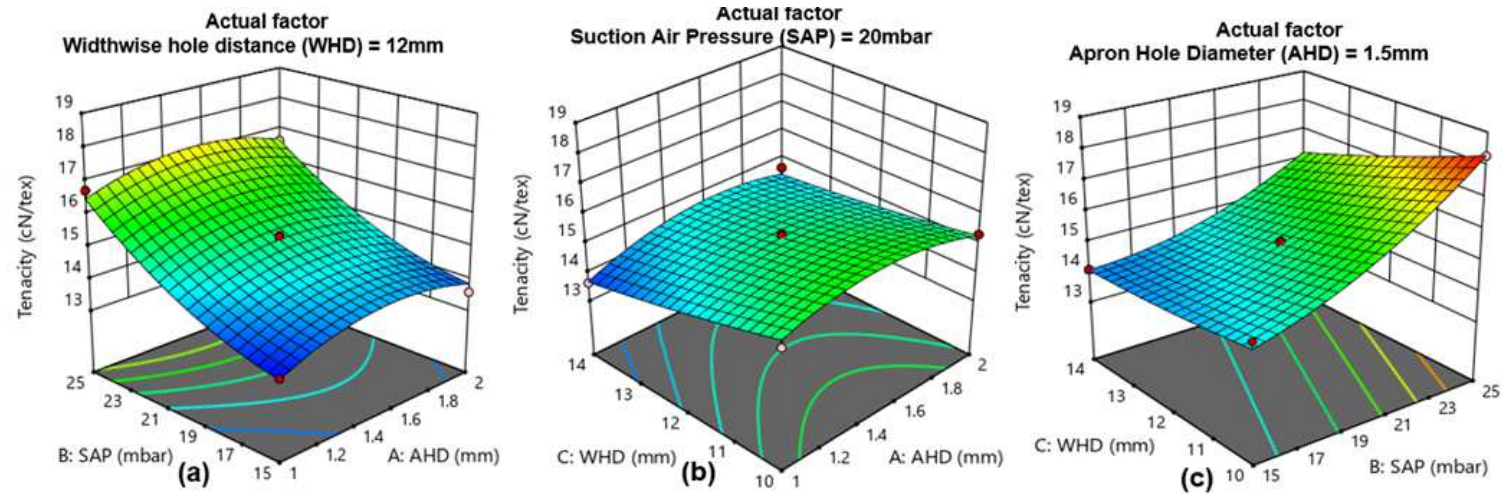

\section{Apron Hole Diameter (AHD) : Suction Air Pressure (SAP) : Widthwise hole distance (WHD)}

Figure 21. Factor interaction effect with a 3D graph for the tenacity of $20 \mathrm{Ne}$ yarn.

\subsubsection{Thin Place $(-50 \% / \mathrm{km})$}

The analysis of ANOVA as shown in Table 13 shows the model F-value obtained in the present study was 1.00 implies the model is not significant. In this study, there are no significant model terms.

Table 13. Analysis of ANOVA for the thin place $(-50 \% / \mathrm{km})$ in $20 \mathrm{Ne}$ yarn.

\begin{tabular}{llllll}
\hline \multicolumn{7}{l}{ Response 3: Thin place for 20 Ne yarn and suggested ANOVA for the quadratic model } & & \\
\hline Source & Sum of Squares & df & Mean Square & F-value & p-value \\
\hline Model & 2360.58 & 9 & 262.29 & 1.00 & 0.5094 \\
A-Apron hole diameter & 136.13 & 1 & 136.13 & 0.5216 & 0.4936 \\
B-Suction pressure & 72.00 & 1 & 72.00 & 0.2759 & 0.6156 \\
C-Widthwise hole distance & 435.13 & 1 & 435.13 & 1.67 & 0.2376 \\
AB & 110.25 & 1 & 110.25 & 0.4224 & 0.5365 \\
AC & 144.00 & 1 & 144.00 & 0.5517 & 0.4818 \\
BC & 650.25 & 1 & 650.25 & 2.49 & 0.1585 \\
$\mathrm{~A}^{2}$ & 8.85 & 1 & 8.85 & 0.0339 & 0.8591 \\
$\mathrm{~B}^{2}$ & 626.69 & 1 & 626.69 & 2.40 & 0.1652 \\
$\mathrm{C}^{2}$ & 209.27 & 1 & 209.27 & 0.8018 & 0.4003 \\
Residual & 1826.95 & 7 & 260.99 & & \\
Lack of Fit & 1205.75 & 3 & 401.92 & 2.59 & 0.1904 \\
Pure Error & 621.20 & 4 & 155.30 & & \\
Cor Total & 4187.53 & 16 & & & not significant \\
\hline
\end{tabular}

\subsubsection{Thick Place $(+50 \% / \mathrm{km})$}

Analysis of ANOVA in Table 14 shows the model F-value obtained was 40.05 implies the model is significant. In this study, $\mathrm{A}, \mathrm{B}, \mathrm{C}, \mathrm{BC}$, and $\mathrm{A}^{2}$ are significant model terms.
However, interaction effect $\mathrm{AB}, \mathrm{AC}$, and quadratic terms $\mathrm{B}^{2}$ and $\mathrm{C}^{2}$ are not significant model terms. Thus, interaction effects have no significant effect on thick place $(+50 \% / \mathrm{km})$ of $20 \mathrm{Ne}$ yarn.

Table 14. Analysis of ANOVA for the thick place $(+50 \% / \mathrm{km})$ in 20 Ne yarn.

\begin{tabular}{llllll}
\hline \multicolumn{2}{l}{ Response 4: Thick place of 20 Ne yarn and suggested ANOVA for the quadratic model } & & \\
\hline Source & Sum of Squares & df & Mean Square & F-value & p-value \\
\hline Model & $2.930 \mathrm{E}+05$ & 9 & 32556.88 & 40.05 & $<0.0001$ \\
A-Apron hole diameter & 79202.00 & 1 & 79202.00 & 97.43 & $<0.0001$ \\
B-Suction air pressure & $1.729 \mathrm{E}+05$ & 1 & $1.729 \mathrm{E}+05$ & 212.66 & $<0.0001$ \\
\hline
\end{tabular}




\begin{tabular}{llllll}
\hline \multicolumn{2}{l}{ Response 4: Thick place of 20 Ne yarn and suggested ANOVA for the quadratic model } & & \\
\hline Source & Sum of Squares & df & Mean Square & F-value & p-value \\
\hline C-Widthwise hole distance & 23544.50 & 1 & 23544.50 & 28.96 & 0.0010 \\
$\mathrm{AB}$ & 272.25 & 1 & 272.25 & 0.3349 & 0.5809 \\
$\mathrm{AC}$ & 3422.25 & 1 & 3422.25 & 4.21 & 0.0793 \\
$\mathrm{BC}$ & 4556.25 & 1 & 4556.25 & 5.61 & 0.0498 \\
$\mathrm{~A}^{2}$ & 5062.55 & 1 & 5062.55 & 6.23 & 0.0413 \\
$\mathrm{~B}^{2}$ & 3620.87 & 1 & 3620.87 & 4.45 & 0.0727 \\
$\mathrm{C}^{2}$ & 846.02 & 1 & 846.02 & 1.04 & 0.3416 \\
Residual & 5690.20 & 7 & 812.89 & & 0.0989 \\
Lack of Fit & 4325.00 & 3 & 1441.67 & 4.22 & not significant \\
Pure Error & 1365.20 & 4 & 341.30 & & \\
Cor Total & $2.987 \mathrm{E}+05$ & 16 & & & \\
\hline
\end{tabular}

For predicting thick place $(+50 \% / \mathrm{km})$ of yarn regression model from analyzed ANOVA in terms of coded parameters after rejecting nonsignificant model is given in Equation (7). The linear effects of apron hole diameter, and suction pressure has a negative correlation with the thick place of 20 $\mathrm{Ne}$ as revealed in Equation (7). The suction pressure (B) had the highest $\mathrm{F}$-value of 212.66 suggesting that it had the most significant influence on the thick place $(+50 \% / \mathrm{km})$ for $20 \mathrm{Ne}$ yarn. From the analyzed result and developed model, it can be concluded that the thick place $(+50 \% / \mathrm{km})$ for $20 \mathrm{Ne}$ yarn decreases significantly as the suction pressure and hole diameter increase. Thus, a model has been developed for predicting thick place for different yarn counts at various apron hole diameters, suction pressure, and hole in the modified G35 ring.

$$
\text { Thick place }(+50 \% / \mathrm{km})=+620.4-99.5 \mathrm{~A}-147 \mathrm{~B}+54.25 \mathrm{C}+33.75 \mathrm{BC}+34.68 \mathrm{~A}^{2}
$$

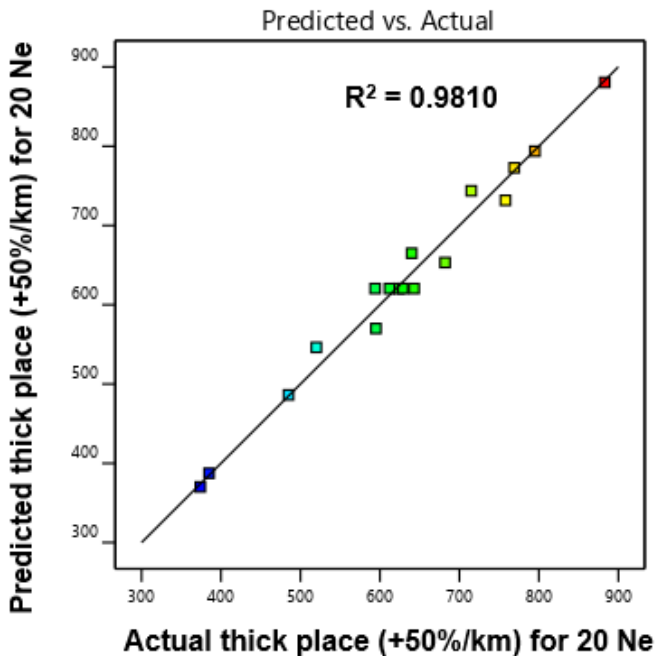

Figure 22. Relationship between actual and predicted thick place for $20 \mathrm{Ne}$.
Therefore, regression coefficient $\mathrm{R}^{2}$ of 0.9810 as shown in Figure 22 is closer to one indicates that correlation is best fitted for predicting thick place from ANOVA. This suggests that the analyzed factors explain $98.10 \%$ of thick place for $20 \mathrm{Ne}$ yarn and that the model could not explain only $1.9 \%$ of the variation of the thick place. Hence, a high correlation is realized between predicted and actual value for the thick place $(+50 \% / \mathrm{km})$ of $20 \mathrm{Ne}$ yarn. Hence, the quadratic model is confirmed to predict the thick place for different yarn counts spun on the modified G 35 ring.

Figure 23 shows that the apron hole diameter, suction air pressure, and widthwise hole distance has a significant effect on the thick place $(+50 \% / \mathrm{km})$ of $20 \mathrm{Ne}$ yarn. Hence, from the result, it can be concluded that the thick place of $20 \mathrm{Ne}$ was decreased as suction pressure increases significantly. Thus, in this study, suction pressure has a more significant effect on thick place of $20 \mathrm{Ne}$.
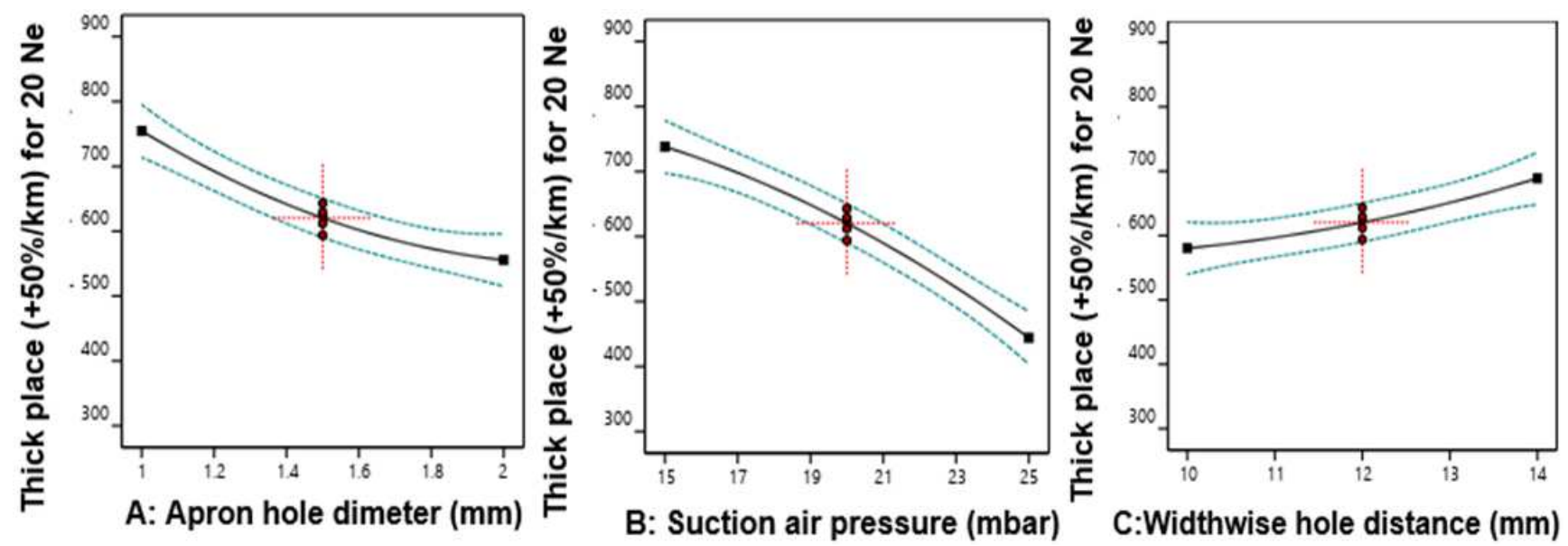

Figure 23. Effect of apron hole diameter, suction pressure, and widthwise hole distance on thick place (+50\%/km) in $20 \mathrm{Ne}$ yarn. 
Figure 24 (a) shows that the minimum thick place $(+50 \% / \mathrm{km})$ obtained was 385 when $2 \mathrm{~mm}$ apron hole diameter and 25 mbar suction air pressure were used with a constant widthwise hole distance of $12 \mathrm{~mm}$ as shown in Table 10 above. Even though, the model interaction effects of hole diameter and suction pressure at $12 \mathrm{~mm}$ hole distance are not significant. Also, in Figure 24 (b) the minimum thick place obtained was 485 when $2 \mathrm{~mm}$ hole diameter and 10 mm widthwise hole distance was used at a constant suction pressure of 20 mbar. Even if, the interaction effect between apron hole diameter and widthwise hole distance has no significant effect.

As shown in Figure 24 (c) the minimum thick place obtained was 374 when 25 mbar suction pressure and $10 \mathrm{~mm}$ widthwise hole distance was used at a constant apron hole diameter of $1.5 \mathrm{~mm}$ as shown in Table 10 above. Thus, from the result, it can be concluded that thick places for $20 \mathrm{Ne}$ were decreased with an increase in suction pressure. The result is shown in Figure 24 (c) was best when compared with all other combinations. Therefore, from the experimental result, it can be concluded that the thick place of $20 \mathrm{Ne}$ decreases with an increase in suction pressure.
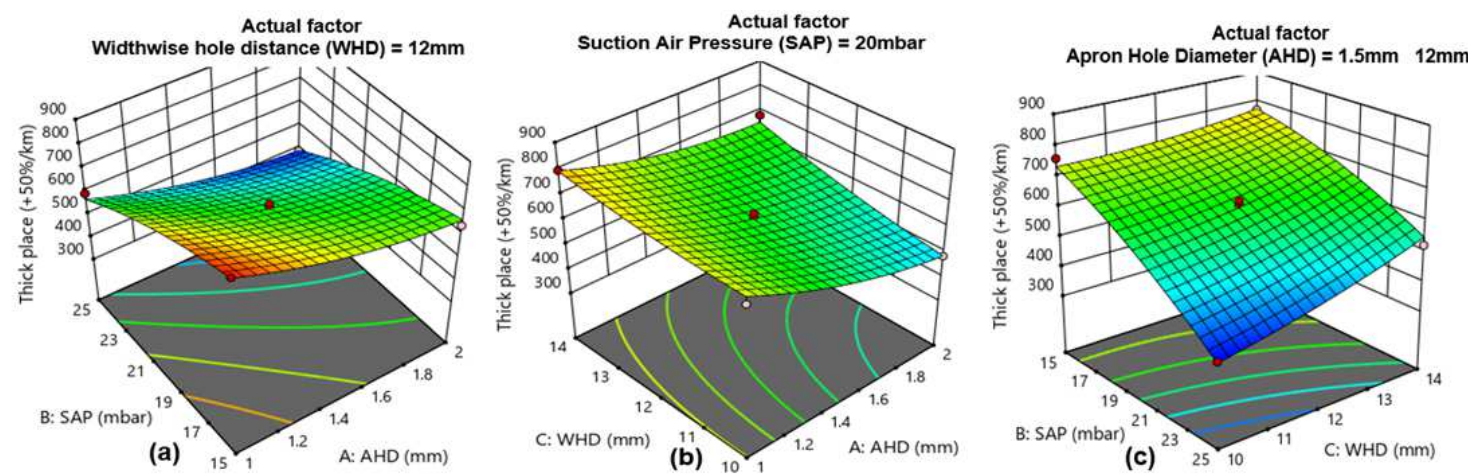

Apron Hole Diameter (AHD) : Suction Air Pressure (SAP) : Widthwise hole distance (WHD)

Figure 24. Factor interaction with a $3 \mathrm{D}$ graph for the thick place $(+50 \% / \mathrm{km})$ of $20 \mathrm{Ne} .4 .2 .5 . \mathrm{Nep}(+200 \% / \mathrm{km})$.

The analysis of ANOVA in Table 15 shows the model Fvalue obtained in the present study was 1.28 implies the model is not significant. In this study, there are no significant model terms meaning apron hole diameter, suction pressure, and widthwise hole distance has not significant effect on nep $(+200 \% / \mathrm{km})$ for $20 \mathrm{Ne}$ yarn.

Table 15. Analysis of ANOVA for nep $(+200 \% / \mathrm{km})$ in 20 Ne yarn.

\begin{tabular}{|c|c|c|c|c|c|c|}
\hline Source & Sum of Squares & df & Mean Square & F-value & p-value & \\
\hline Model & 76603.42 & 9 & 8511.49 & 1.28 & 0.3797 & not significant \\
\hline A-Apron hole diameter & 8911.12 & 1 & 8911.12 & 1.34 & 0.2845 & \\
\hline B-Suction pressure & 1081.12 & 1 & 1081.12 & 0.1629 & 0.6985 & \\
\hline C-Widthwise hole distance & 15312.50 & 1 & 15312.5 & 2.31 & 0.1725 & \\
\hline $\mathrm{AB}$ & 36.00 & 1 & 36.00 & 0.0054 & 0.9433 & \\
\hline $\mathrm{AC}$ & 13110.25 & 1 & 13110.2 & 1.98 & 0.2026 & \\
\hline $\mathrm{A}^{2}$ & 4420.04 & 1 & 4420.04 & 0.6661 & 0.4413 & \\
\hline $\mathrm{B}^{2}$ & 18009.09 & 1 & 18009.0 & 2.71 & 0.1435 & \\
\hline $\mathrm{C}^{2}$ & 3701.57 & 1 & 3701.57 & 0.5578 & 0.4795 & \\
\hline Residual & 46451.05 & 7 & 6635.86 & & & \\
\hline Lack of Fit & 37116.25 & 3 & 12372.0 & 5.30 & 0.0704 & not significant \\
\hline Pure Error & 9334.80 & 4 & 2333.70 & & & \\
\hline Cor Total & $1.231 \mathrm{E}+05$ & 16 & & & & \\
\hline
\end{tabular}

\subsubsection{Optimization of Apron Hole Diameter, Suction Air Pressure and Width-wise Hole Distance for $20 \mathrm{Ne}$ Yarn}

Table 16 shows that the optimized solution of apron hole diameter, suction pressure, and widthwise hole distance for properties of $20 \mathrm{Ne}$ yarn. The desirability for $20 \mathrm{Ne}$ yarn was found to be 0.78 shows that the optimized solution for the given factor fits a good result.

Table 16. Optimized solution for 20 Ne yarn.

\begin{tabular}{|c|c|c|c|c|c|c|c|c|c|}
\hline $\begin{array}{l}\text { Apron hole } \\
\text { diameter }(\mathrm{mm})\end{array}$ & $\begin{array}{l}\text { Suction pressure } \\
\text { (mbar) }\end{array}$ & $\begin{array}{l}\text { Widthwise hole } \\
\text { distance }(\mathrm{mm})\end{array}$ & $\begin{array}{l}\text { Tenacity } \\
\text { (cN/tex) }\end{array}$ & $\begin{array}{l}\text { Hairiness } \\
\text { Index (H) }\end{array}$ & $\begin{array}{l}\text { Nep } \\
(+200 \% / \mathbf{k m})\end{array}$ & $\begin{array}{l}\text { Thin place } \\
(-50 \% / k m)\end{array}$ & $\begin{array}{l}\text { Thick place } \\
(+50 \% / \mathbf{k m})\end{array}$ & Desirability & \\
\hline 1.757 & 25.000 & 11.668 & 17.200 & 7.134 & 924.602 & 31.816 & 389.633 & 0.780 & Selected \\
\hline
\end{tabular}




\subsection{Comparison of 40 Ne Conventional Yarn with Modified Ring Yarn}

The hairiness index of $40 \mathrm{Ne}$ modified yarn was reduced by $16.25 \%$ as compared to conventional yarn. Besides tenacity of $40 \mathrm{Ne}$ modified yarn was increased by $12.7 \%$ as compared to conventional as shown in Table 17. Thick place
$(+50 \% / \mathrm{km})$ and thin place $(-50 \% / \mathrm{km})$ for $40 \mathrm{Ne}$ modified yarns were reduced by $14.625 \%$ and $17.42 \%$ respectively. The nep $(+200 \% / \mathrm{km})$ comparison between modified and conventional $40 \mathrm{Ne}$ yarn was not done as the nep value has no significant effect on modified yarn.

Table 17. Mean comparison between conventional and modified $40 \mathrm{Ne}$ yarn.

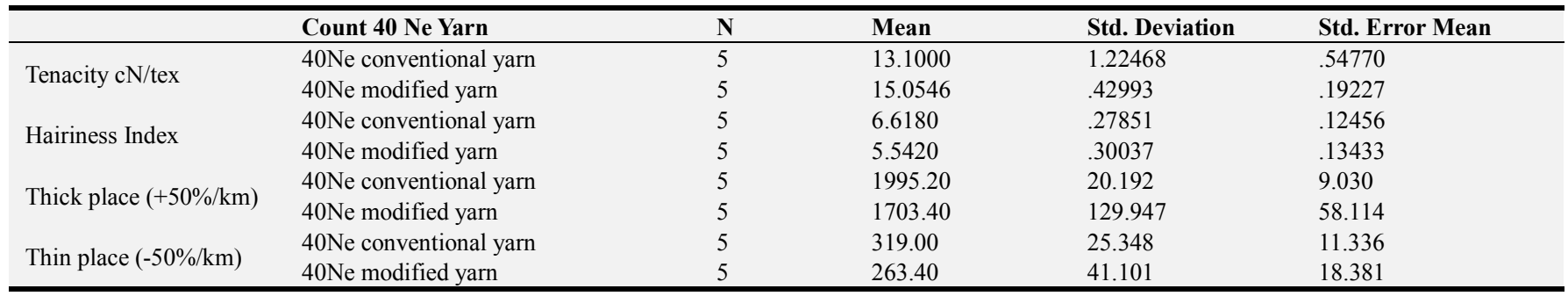

A significant improvement in hairiness, tenacity, thick place $(+50 \% / \mathrm{km})$, and thin place $(-50 \% / \mathrm{km})$ of modified yarn was observed as compared to conventional yarn as shown in Table 18.

Table 18. Independent t-test comparison between conventional and modified $40 \mathrm{Ne}$.

\begin{tabular}{|c|c|c|c|c|c|c|c|}
\hline & \multicolumn{7}{|c|}{ Independent samples t-test for equality of means } \\
\hline & \multirow{2}{*}{$\mathbf{t}$} & \multirow{2}{*}{ Df } & \multirow{2}{*}{ Sig.(2-tailed) } & \multirow{2}{*}{ Mean d/nce } & \multirow{2}{*}{ Std. Error d/nce } & \multicolumn{2}{|c|}{$95 \%$ confidence interval $\mathrm{d} / \mathrm{nce}$} \\
\hline & & & & & & Lower & Upper \\
\hline Tenacity & -3.36 & 4.9 & .020 & -1.95 & .5804 & -3.4493 & -.459 \\
\hline Hairiness & 5.87 & 7.9 & .000 & 1.076 & .1831 & .65315 & 1.498 \\
\hline Thick place $(+50 \% / \mathrm{km})$ & 4.96 & 4.1 & .007 & 291.8 & 58.81 & 131.43 & 452.1 \\
\hline Thin place $(-50 \% / \mathrm{km})$ & 2.57 & 6.6 & .038 & 55.60 & 21.59 & 3.999 & 107.2 \\
\hline
\end{tabular}

\subsection{Comparison of 40 Ne Modified Yarn with Uster Statistics 2018}

The hairiness of modified yarn as compared with Uster 2018 at $75 \%$ USP shows that the difference was not significant. Because the p-value for hairiness of $40 \mathrm{Ne}$ between the modified with Uster was 0.109 which is greater than alpha (0.05). Thus, the hairiness of yarn spun with a modified G35 ring achieves Uster 2018 standard at 75\% USP. However, yarn tenacity, thick place, and thin place comparison between modified with Uster 2018 show a significant difference. Because the p-value between the modified yarn with Uster is smaller than the alpha value (0.05) as shown in Table 19. Thus, the tenacity, thick, and thin place of modified yarn was lower as compared with Uster 2018 at 75\% Uster Statistics percentile (USP).

Table 19. Comparison of 40 Ne yarn between modified and Uster 2018 at $75 \%$ USP.

\begin{tabular}{|c|c|c|c|c|c|}
\hline & Count 40 Ne Yarn & $\mathbf{N}$ & Mean & Std. Deviation & Std. Error Mean \\
\hline \multirow{2}{*}{ Tenacity } & 40Ne modified yarn & 5 & 15.0546 & .42993 & .19227 \\
\hline & $40 \mathrm{Ne}$ on Uster 2018 & 5 & 15.5600 & .00000 & .00000 \\
\hline \multirow{2}{*}{ Hairiness Index } & 40Ne modified yarn & 5 & 5.5420 & .30037 & .13433 \\
\hline & $40 \mathrm{Ne}$ on Uster 2018 & 5 & 5.3000 & .00000 & .00000 \\
\hline \multirow{2}{*}{ Thick place $(+50 \% / \mathrm{km})$} & 40Ne modified yarn & 5 & 1703.40 & 129.947 & 58.114 \\
\hline & $40 \mathrm{Ne}$ on Uster 2018 & 5 & 400.00 & .000 & .000 \\
\hline Thin place $(-50 \% / \mathrm{km})$ & $40 \mathrm{Ne}$ modified yarn & 5 & 263.40 & 41.101 & 18.381 \\
\hline
\end{tabular}

Hairiness index of modified $40 \mathrm{Ne}$ yarns was not significant as compared with Uster 2018 at $75 \%$ USP. As the p-values 0.109 is greater than alpha (0.05) as shown in Table 20 .

Table 20. Independent sample t-test mean comparison of modified with Uster 2018.

\begin{tabular}{|c|c|c|c|c|c|c|}
\hline \multicolumn{7}{|c|}{ Independent Samples t-test for Equality of Means } \\
\hline & \multirow{2}{*}{ Df } & \multirow{2}{*}{ Sig. (2-tailed) } & \multirow{2}{*}{ Mean $d /$ nce } & \multirow{2}{*}{ Std. Error d/nce } & \multicolumn{2}{|c|}{$95 \%$ confidence Interval $d /$ nce } \\
\hline & & & & & Lower & Upper \\
\hline Tenacity & 8 & .030 & -.5054 & .19227 & -.9487 & -.0620 \\
\hline Hairiness & 8 & .109 & .24200 & .13433 & -.0677 & .55176 \\
\hline
\end{tabular}




\begin{tabular}{|c|c|c|c|c|c|c|}
\hline \multicolumn{7}{|c|}{ Independent Samples t-test for Equality of Means } \\
\hline & \multirow{2}{*}{ Df } & \multirow{2}{*}{ Sig. (2-tailed) } & \multirow{2}{*}{ Mean d/nce } & \multirow{2}{*}{ Std. Error d/nce } & \multicolumn{2}{|c|}{ 95\% confidence Interval $d / n c e$} \\
\hline & & & & & Lower & Upper \\
\hline Thick place $(+50 \% / \mathrm{km})$ & 8 & .000 & 1303.4 & 58.114 & 1169.3 & 1437.4 \\
\hline Thin place $(-50 \% / \mathrm{km})$ & 8 & .000 & 207.40 & 18.381 & 165.01 & 249.78 \\
\hline
\end{tabular}

\subsection{Comparison of $20 \mathrm{Ne}$ Yarn Spun with Conventional and Modified G35 Ring}

The hairiness index of $20 \mathrm{Ne}$ modified yarn was reduced by $8.87 \%$ as compared to conventional as shown in Table 21 .
The tenacity of $20 \mathrm{Ne}$ modified yarn was increased by $7.42 \%$ as compared to conventional. The thick place $(+50 \% / \mathrm{km})$ of modified $20 \mathrm{Ne}$ yarn was reduced by $18.27 \%$ as compared to conventional.

Table 21. Mean comparison between conventional and modified 20 Ne yarn.

\begin{tabular}{lllll}
\hline & Count 20 Ne Yarn & N & Mean & Std. Deviation \\
\hline \multirow{2}{*}{ Tenacity cN/tex } & 20 Ne conventional yarn & 5 & 15.218 & .25479 \\
& 20 Ne modified yarn & 5 & 16.442 & .37097 \\
Hairiness index & 20 Ne conventional yarn & 5 & 7.6640 & .11395 \\
& 20 Ne modified yarn & 5 & 6.9800 & .16590 \\
Thick place $(+50 \% / \mathrm{km})$ & 20 Ne conventional yarn & 5 & .17015 & .09026 \\
& 20 Ne modified yarn & 5 & 371.60 & 24.765 \\
\hline
\end{tabular}

The independent t-test analysis as shown in Table 22 shows that there is a significant difference in tenacity, hairiness index, and thickness $(+50 \% / \mathrm{km})$ between modified
$20 \mathrm{Ne}$ yarn with conventional yarn. Thus, it is noticed that better tenacity, lower hairiness, and lower imperfection were observed for modified yarn as compared with conventional.

Table 22. Independent t-test comparison between conventional and modified $20 \mathrm{Ne}$.

\begin{tabular}{|c|c|c|c|c|c|c|c|}
\hline & \multicolumn{7}{|c|}{ Independent Samples t-test for Equality of Means } \\
\hline & \multirow{2}{*}{$\mathbf{t}$} & \multirow{2}{*}{ Df } & \multirow{2}{*}{ Sig. (2-tailed) } & \multirow{2}{*}{ Mean d/nce } & \multirow{2}{*}{ Std. error $d /$ nce } & \multicolumn{2}{|c|}{$95 \%$ interval $\mathrm{d} /$ nce } \\
\hline & & & & & & Lower & Upper \\
\hline Tenacity & -6.08 & 7.08 & .000 & -1.22 & .2012 & -1.6987 & -.74926 \\
\hline Hairiness & 5.79 & 7.77 & .000 & .684 & .1180 & .41041 & .95759 \\
\hline Thick place $(+50 \% / \mathrm{km})$ & 5.92 & 7.80 & .000 & 86.2 & 14.55 & 52.492 & 119.90 \\
\hline
\end{tabular}

\subsection{Comparison of 20 Ne Modified Yarn with Uster 2018 at $75 \%$ USP}

As compared with Uster 2018 with $75 \%$ Uster statistics percentile the hairiness index of the $20 \mathrm{Ne}$ modified yarn was reduced by $4.01 \%$ shown in Table 23 . The $5.66 \%$ tenacity of the modified yarn was lower as compared to Uster 2018 with $75 \%$ USP. Moreover, the thick place of $20 \mathrm{Ne}$ modified yarn was $48.36 \%$ higher as compared to Uster 2018.

Table 23. Comparison between modified 20 Ne yarn with Uster 2018 at $75 \%$ USP

\begin{tabular}{|c|c|c|c|c|c|}
\hline & Count 20 Ne Yarn & $\mathbf{N}$ & Mean & Std. Deviation & Std. Error Mean \\
\hline \multirow{2}{*}{ Tenacity cN/tex } & $20 \mathrm{Ne}$ modified yarn & 5 & 16.442 & .37097 & .16590 \\
\hline & $20 \mathrm{Ne}$ on Uster 2018 & 5 & 17.430 & .00000 & .00000 \\
\hline \multirow{2}{*}{ Hairiness Index } & $20 \mathrm{Ne}$ modified yarn & 5 & 6.9800 & .17015 & .07609 \\
\hline & $20 \mathrm{Ne}$ on Uster 2018 & 5 & 6.7000 & .00000 & .00000 \\
\hline \multirow{2}{*}{ Thick place $(+50 \% / \mathrm{km})$} & 20 Ne modified yarn & 5 & 385.40 & 21.114 & 9.442 \\
\hline & $20 \mathrm{Ne}$ on Uster 2018 & 5 & 199.00 & .000 & .000 \\
\hline
\end{tabular}

A significant difference was observed at 0.005 significance between the $20 \mathrm{Ne}$ modified yarn and Uster 2018 to the hairiness index, tenacity, and thick place $(+505 / \mathrm{km})$. The 20 Ne modified yarn has lower tenacity and higher hairiness and thick place as compared with the Uster 2018 at $75 \%$ Uster statistics.

\section{Conclusion}

A technique has been developed by modifying the bottom aprons with perforation in two rows and the perforated nose bars were fabricated and fitted in conventional Reiter G35 ring frame. Suction pressure was applied and two counts of 29.52 Tex $(20 \mathrm{Ne})$ and $14.76 \mathrm{Tex}(40 \mathrm{Ne})$ were spun. To produce modified yarn 17 combinations of apron hole diameter, suction pressure, and widthwise hole distance was used Relationship between actual and predicted values for all properties were formulated using quadratic regression model for both $40 \mathrm{Ne}$ and 20s $\mathrm{Ne}$ yarn. Optimization was done by Design expert software with the numerical optimization method. The optimized solution of apron hole diameter, suction pressure, and widthwise hole distance for properties of $40 \mathrm{Ne}$ and $20 \mathrm{~S} \mathrm{Ne}$ yarn specifically yarn tenacity, hairiness, thin place, thick place, and nep were derived and 
indicated. The yarn results were compared with conventional and Uster 2018 75\% USP. A significant improvement in yarn hairiness index, tenacity, thin place and thick place of $40 \mathrm{Ne}$ yarn spun on modified $\mathrm{G} 35$ ring were observed in comparing with conventional yarn. Moreover, the hairiness index, tenacity and thick place of $20 \mathrm{Ne}$ modified yarn were improved significantly. As compared with the Uster statistics the hairiness index of the modified $40 \mathrm{Ne}$ yarn was similar as compared with Uster 2018 at $75 \%$ Uster statistics percentile. However, yarn tenacity, thick place, and thin place comparison between modified with Uster 2018 show a significant difference. The $20 \mathrm{Ne}$ modified yarn has lower tenacity and higher hairiness and thick place as compared with the Uster 2018 at $75 \%$ Uster statistic. Thus, the modified G35 method of yarn condensing has a great capability to be used as an alternative method of conventional spinning as it is capable of producing better quality yarn.

\section{Future Works}

The suction pressure, apron hole diameter, and width-wise suction hole distance were investigated using $20 \mathrm{Ne}$ and 40 $\mathrm{Ne}$ yarn on a modified G 35 ring and their effects on yarn quality were revealed in this study. The work and ideas proposed in this thesis can be extended in the future and possibilities of further improvements. The newly proposed methods are in an early stage of development and may be researched further to improve accuracy, performance, and application. Therefore, this research will open a good opportunity for researchers. Hence the results of this study proposed several new ideas for research in the future. The following ideas will be proposed for future work.

1) For future researchers, the fiber migration for $20 \mathrm{Ne}$ and $40 \mathrm{Ne}$ yarn spun on the modified G 35 ring was not done yet.

2) The effect of suction pressure, apron hole diameter, and width-wise suction hole distance on yarn fault classimates for $20 \mathrm{Ne}$ and $40 \mathrm{Ne}$ yarn spun on modified G 35 ring were not done.

3) The comparisons of the yarn spun on the modified G 35 with compact yarn were not done.

\section{References}

[1] Uddin, F., Introductory Chapter: Textile Manufacturing Processes, in Textile Manufacturing Processes. 2019, Intech Open.

[2] Mohan, J., Global Textile Industry: Recent Trends in the Market. 2019. 2019.

[3] Kotb, N., Predicting yarn quality performance based on fibers types and yarn structure. Life Science Journal, 2012. 9 (3): p. 1009-1015.

[4] Kumar, A., S. Ishtiaque, and K. Salhotra. Compact spinning: a critical review. in ASME International Mechanical Engineering Congress and Exposition. 2003.
[5] Saha, S. K. and J. Hossen, Impact of Doubling and Auto leveling in Draw Frame on the Quality of Rotor-Spun Yarns. 2019.

[6] Saravanan, A. R. and S. Subramanian, Study on the Change in Characteristics of Ring Yarn during Post Spinning and Yarn Dyeing Operations. Fibres \& Textiles in Eastern Europe, 2018

[7] Lawrence, C. A., Fundamentals of spun yarn technology. 2003: Crc Press.

[8] Lawrence, C. A., Advances in yarn spinning technology. 2010: Elsevier.

[9] Patil, N. P., P. Rachivkar, and A. M. ArurKamundi, Imrprove productivity of the ring frame. The Indian Textile Journal, 2011.

[10] Thilagavathi, G. and T. Karthik, Process control and yarn quality in spinning. 2016: CRC Press.

[11] Kumar, R. S., Process management in spinning. 2014: CRC Press.

[12] Rengasamy, R., A. Patnaik, and H. Punekar, Studies on reduction of yarn hairiness by nozzles in ring spinning and winding by airflow simulation. Fibers and Polymers, 2006. 7 (3): p. 317-322

[13] El-Sayed, M. and S. Sanad, Compact spinning technology, in Advances in Yarn Spinning Technology. 2010, Elsevier. p. 237-260.

[14] Ahmad, M. M., Future spinning technology: Compact spinning. PTJ, 2009. 58 (2): p. 52-54.

[15] Bhokare, A. D. K. a. P. D., Overview of Various Compact Spinning Mechanisms. Fiber to fashion, 2009.

[16] Altas, S. and H. Kadoğlu, Comparison of conventional ring, mechanical compact and pneumatic compact yarn spinning systems. Journal of Engineered Fibers and Fabrics, 2012.7 (1): p. 155892501200700110 .

[17] Almetwally, A. A., et al., Comparison between physical properties of ring-spun yarn and compact yarns spun from different pneumatic compacting systems. 2015.

[18] Abou-Nassif, G. A., A comparative study between physical properties of compact and ring yarn fabrics produced from medium and coarser yarn counts. Journal of Textiles, 2014.

[19] Murugan, R., C. Vigneswaran, and A. Ghosh, Novel technique for improving yarn quality and reducing hairiness in conventional ring frame. 2011.

[20] Qiu, H., et al., A novel method to reduce hairiness level of ring spun yarn. Fibers and Polymers, 2012. 13 (1): p. 104-109.

[21] Yilmaz, D. and M. Usal, The effect of different nozzle configurations on airflow behaviour and yarn quality. International Journal of Industrial and Manufacturing Engineering, 2012. 6 (11): p. 2310-2314.

[22] Klein, W. and H. Stalder, The Rieter manual of spinning. Rieter, Winterthur, 2014.

[23] Yilmaz, D. and M. R. Usal, Effect of nozzle structural parameters on hairiness of compact-jet yarns. Journal of Engineered Fibers and Fabrics, 2012. 7 (2): p. 155892501200700209 . 
[24] Yilmaz, D. and M. R. Usal, Improvement in yarn hairiness by the siro-jet spinning method. Textile Research Journal, 2013. 83 (10): p. 1081-1100.

[25] YU, Q. H. L. Q. F., L. Qiaoli, and Y. Fu, EFFECTS OF GEOMETRY ON THE PERFORMANCE OF SWIRL NOZZLE. Tekstil ve Konfeksiyon, 2015. 25 (1): p. 61-65.

[26] Zhang, X. C., H. X. Zhang, and L. D. Cheng. Effect of Negative Pressure on Yarn Quality in Compact Spinning with Inspiratory Groove. in Advanced Materials Research. 2013. Trans Tech Publ.

[27] Yilmaz, D. and M. R. Usal, A comparison of compact-jet, compact, and conventional ring-spun yarns. Textile Research Journal, 2011.81 (5): p. 459-470.

[28] Wang, X., Recent Research on Yarn Hairiness Testing and Reduction: Part - Reduction of Yarn Hairiness. Research Journal of Textile and Apparel, 1999. 3 (1): p. 1-8.

[29] Tyagi, G., Yarn structure and properties from different spinning techniques, in Advances in Yarn Spinning Technology. 2010, Elsevier. p. 119-154.

[30] Yang, S. and S. Gordon, Accurate prediction of cotton ringspun yarn quality from high-volume instrument and mill processing data. Textile Research Journal, 2017. 87 (9): p. 1025-1039.
[31] Stadler, H., The Rieter Manual of Spinning. 2016, Volume.

[32] Chakrabortty, A., A. HOSSAIN, and J. GHOSH, Study on the Effect of Air Suction Pressure on the Quality of Compact Yarn by Changing the Frequency of Inverter. Tekstil ve Mühendis, 2020. 27 (119): p. 154-158.

[33] Yilmaz, D. and M. R. Usal, Characterization of Jetring yarn structure and properties. Science and Engineering of Composite Materials, 2011. 18 (3): p. 127-137.

[34] Sundaresan, S., et al., A novel method of hairiness reduction by modified lappet design and separator in conventional ring frame.

[35] Almetwally, A. A. and M. M. Salem, Comparison between mechanical properties of fabrics woven from compact and ring spun yarns. Autex Research Journal, 2010. 10 (1): p. 3540 .

[36] Liu, X., et al., Research on pneumatic compact spun yarn quality. The Journal of The Textile Institute, 2015. 106 (4): p. 431-442.

[37] Liu, S. Q., et al. Effect of Siro-Spun Processing Parameters on Properties of 55/45 Flax/Cotton Blended Yarn. in Advanced Materials Research. 2011. Trans Tech Publ. 